\title{
3D printing approaches for cardiac tissue engineering and role of immune modulation in tissue regeneration
}

This article was published in the following Dove Medical Press journal: International Journal of Nanomedicine

\author{
Muhammad Qasim' \\ Farhan $\mathrm{Haq}^{2}$ \\ Min-Hee Kang' \\ Jin-Hoi Kim' \\ 'Department of Stem Cell and \\ Regenerative Biotechnology, \\ Humanized Pig Research Centre \\ (SRC), Konkuk University, Seoul, \\ South Korea; ${ }^{2}$ Department of \\ Biosciences, Comsats University, \\ Islamabad, Pakistan
}

\begin{abstract}
Conventional tissue engineering, cell therapy, and current medical approaches were shown to be successful in reducing mortality rate and complications caused by cardiovascular diseases (CVDs). But still they have many limitations to fully manage CVDs due to complex composition of native myocardium and microvascularization. Fabrication of fully functional construct to replace infarcted area or regeneration of progenitor cells is important to address CVDs burden. Three-dimensional (3D) printed scaffolds and 3D bioprinting technique have potential to develop fully functional heart construct that can integrate with native tissues rapidly. In this review, we presented an overview of $3 \mathrm{D}$ printed approaches for cardiac tissue engineering, and advances in 3D bioprinting of cardiac construct and models. We also discussed role of immune modulation to promote tissue regeneration.
\end{abstract}

Keywords: scaffolds, regeneration, cardiovascular diseases, cell therapy

\section{Introduction}

Cardiovascular diseases (CVDs) are highly prevailing worldwide diseases in terms of morbidity and mortality worldwide, especially in developed countries. ${ }^{1}$ One out of seven deaths is caused by coronary artery disease and the estimated total incidences of myocardial infarction are almost 790,000 per year. ${ }^{1-3}$ Other than loss of native cells in heart tissues, the different pathologic conditions such as atresia, regurgitation, and stenosis also affect the heart valves. ${ }^{4-6}$ Cardiac arrest or heart attack is caused by problem in electrical impulse or blood arteries that supply oxygen and nutrients to heart tissues. ${ }^{7}$ Almost 1 billion cardiomyocytes (CMs) are lost during heart attack. ${ }^{8}$ There is no auto-regeneration or repair process for lost cells, rather the heart forms a scar tissue that blocks the electrical signal and spontaneous contraction. This situation increases the risk of heart failure. Acute myocardial infarction (MI) or end-stage ischemic heart failure is currently managed by cell therapy, coronary artery bypass grafting, left ventricular assist device, and finally heart transplantation. ${ }^{9-12}$ But there is lack of organ donors as compared to demand and also organ transplantation is not always successful due to associated complications of immune rejection. ${ }^{13}$ Among other treatment options available, direct injection of cells to heal MI showed some success to regain muscle function; however, most of the cells after injection were reported to be dead ${ }^{14-16}$ (Figure 1). These injected cells also failed to develop early vascularization and extracellular matrix (ECM), which is important for exchange of materials in tissue repair process. Due to lack of three-dimensional (3D) flexible biomimetic ECM and the supply of nutrients, the survival duration of the injected cells is low. Therefore,
Correspondence: Jin-Hoi Kim Department of Stem Cell and Regenerative Biotechnology, Humanized Pig Research Centre (SRC), Konkuk University, I 20 Gwangjin gu, |43-70 I Seoul, South Korea

Email jhkim54I@konkuk.ac.kr 


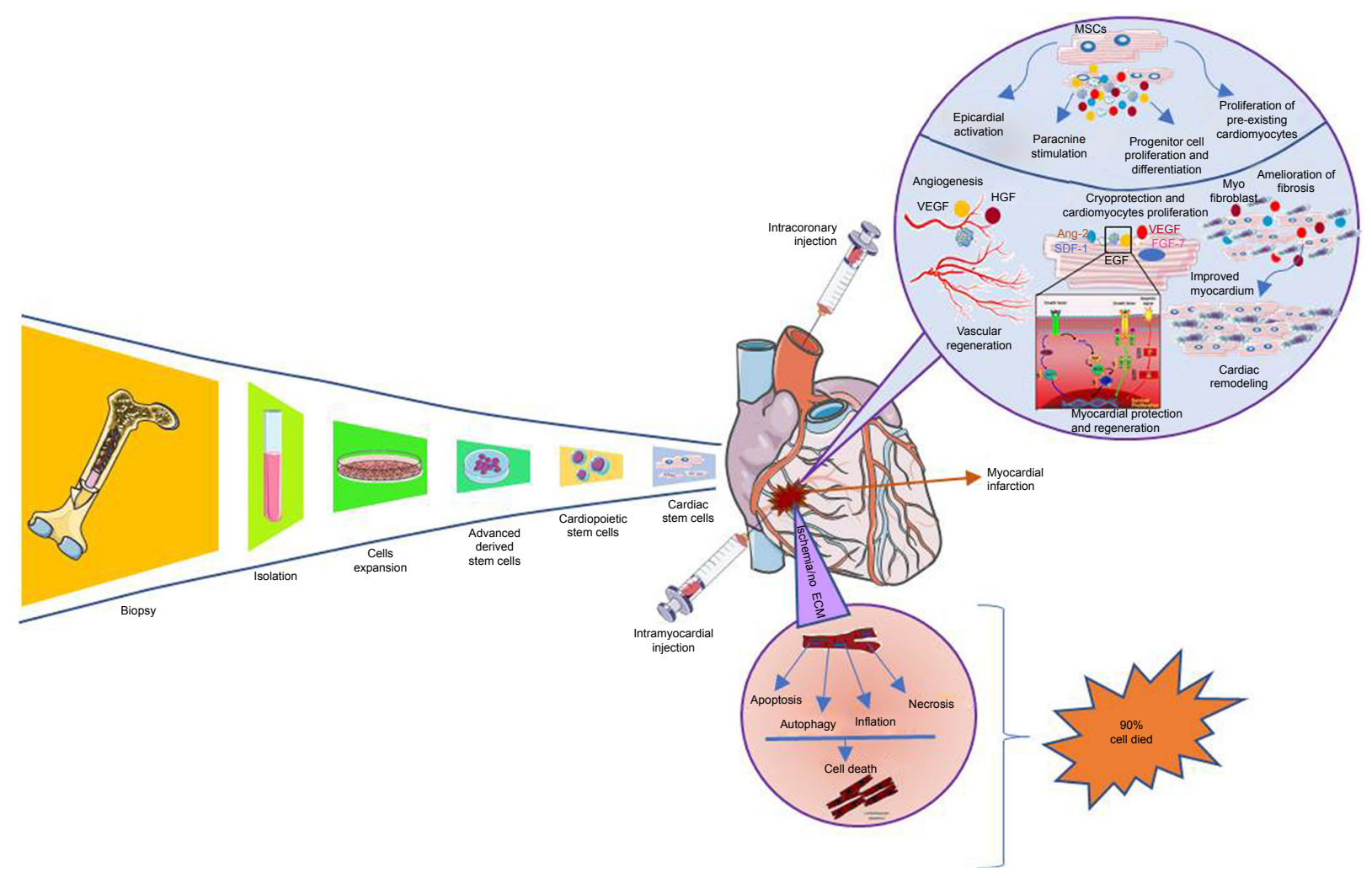

Figure I Cell therapy to treat MI, isolation, injection, repair, and apoptosis.

Abbreviations: HGF, human growth factor; MI, myocardial infarction; MSC, mesenchymal stem cell; VEGF, vascular endothelial growth factor.

$90 \%$ cells die as a result of lack of nutrients supply and exposure to free radicals and inflammatory cytokines present in the surrounding tissue ${ }^{17,18}$ (Figure 1). In cell therapy, bone marrow stem cells are isolated from bone marrow based on density gradient centrifugation. ${ }^{19}$ The resulting product is defined as bone marrow mononuclear cells (BMMNCs), which include bone marrow hematopoietic stem cells, bone marrow mesenchymal stem cells, and committed cells in the various stages of differentiation. The majority of the clinical trials with BMMNCs reported a modest improvement of left ventricular function and cardiac perfusion by enhanced microvascularization. ${ }^{14,20-22}$ Tissue engineering of a largesize cardiac construct is very challenging due to its complex nature (Figure 2). It is tough to mimic the hierarchical property of native myocardium to develop dynamic cardiac tissue with continuous contraction and relaxation. ${ }^{23,24}$ Cardiac tissues are composed of ECM proteins and different cells aligned in a very special order to maintain their spontaneous contraction to pump blood. Keeping in view these challenges there is need of a special tissue engineering technique that can present a scaffold with natural ECM and can hold the CMs and promote their regeneration.

Tissue engineering is a multidisciplinary approach, which combines materials engineering, life sciences, and computer modeling to produce functional scaffolds and artificial tissues construct for biomedical applications. ${ }^{17,25,26}$ Tissue engineering has potential to address all key challenges of cardiac tissue engineering. ${ }^{27}$ In this technique a scaffold with ECM nature was used to support repair or regeneration process. Tissue engineering techniques used mainly three types of materials for cardiac tissue engineering, and those are natural (gelatin, collagen, alginate, chitosan, fibrin, and hyaluronic acid) ${ }^{28-30}$ synthetics [poly (glycolic acid), polycaprolactone (PCL), poly (lactic acid), and poly D,L-lactic-co-glycolic acid (PLGA)],,$^{28,31-33}$ and hybrid (combination of synthetics, natural, and metallic). ${ }^{34}$ These materials are used to fabricate $3 \mathrm{D}$ scaffolds to mimic the native ECM and present similar morphology to cell as they exit from the original organ. An ideal scaffold for cardiac tissue engineering should be biocompatible, biodegradable, and have enough mechanical strength and electrical conductance to perform dynamic functions of the heart. ${ }^{35,36}$

Over a course of time, 3D scaffold-based cell culture technique is proven better as compared to $2 \mathrm{D}$ conventional cell culture techniques, commonly used in academic and industrial labs. ${ }^{37,38}$ In 2D cell culture, cellular morphology is different from native tissue due to extra surface tension and one side cell adhesion in cell culture flask or dish. ${ }^{39}$ Also, 


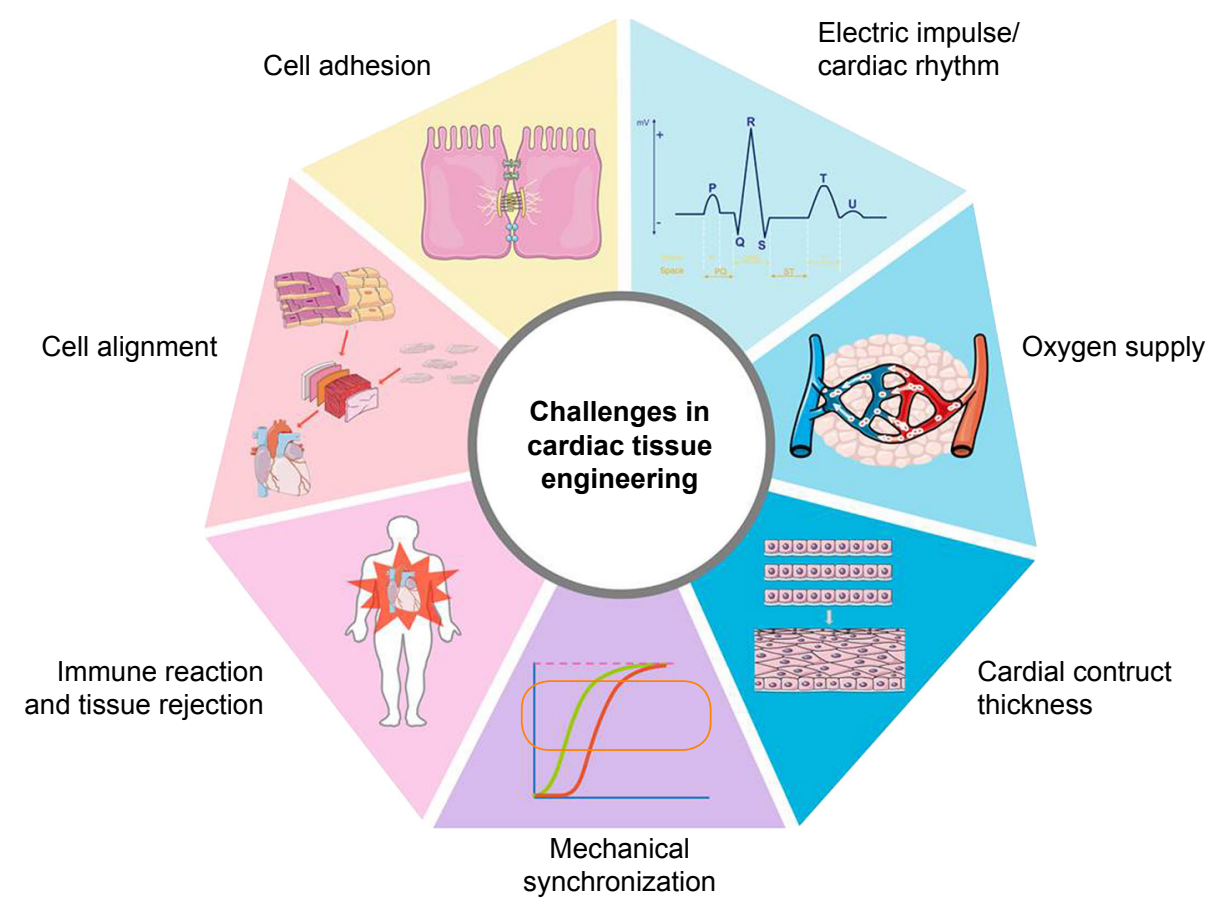

Figure 2 Graphical representation of challenges in cardiac tissue engineering.

monolayer cell culture or single-cell culture cannot sufficiently explain the clinically relevant heart disease models like MI and heart failure. ${ }^{40}$ Furthermore, culture of $\mathrm{CMs}$ within 3D scaffold showed CM alignment and physiology. ${ }^{41}$ Embryonic stem cell (ESC)-derived CMs showed increased expression for contractile functionally related genes, extended sarcomeres, and higher conduction velocities within 3D scaffolds as compared to $2 \mathrm{D}$ monolayers. ${ }^{42}$ Therefore, $3 \mathrm{D}$ tissue engineering strategies can only help in finding the optimum solution for cardiac tissue engineering. Various techniques and designs have been applied to manipulate cell physiology by targeting substrate, topography, material stimulation by electrical or mechanical signal, and coculture. ${ }^{43}$ In 3D tissue engineering techniques, we can use mechanical strain and shear stress, alter calcium dynamics, electric impulse and temperature can simultaneously direct cell alignment, synchronization, differentiation, and maturations of cells to CMs. ${ }^{37,44}$ Further, 3D scaffolds can support coculture or mixture of cell culture, as cardiac tissue engineering required different cells to mimic functions of myocardium. Additionally, it has been observed that $\mathrm{CMs}$ culture with non-CM cells supported the regeneration and growth of tissue-engineered construct. ${ }^{45}$ In some cases, only CMs failed to develop tissue construct when they were cultured alone, as endothelial cells (ECs) are important for vascularization of constructs to match nutrients demand. Coculture of CMs and ECs in 3D scaffolds resulted in functionalized cardiac tissue construct with increased proliferation, amelioration, physiology, and viability of CMs. ${ }^{46}$ These functional cardiac constructs as a result of 3D scaffold-based tissue engineering can also act as an alternative for in vivo drug screening as existing animal models of drug screening does not match exactly with human physiology. ${ }^{47}$ Furthermore, human immune system is much complex as compared to animals' use as disease models for drug screening. Therefore, during drug development when drug is screened through 2D cell culture assays and animals' disease models, screening results are prone to false positive or false negative. In the past decade, more than $20 \%$ drugs are withdrawn from market due to cardiac cytotoxicity including antihistamines (terfenadine and astemizole), benfluorex, sibutramine, prokinetic agents (cisapride), spasmolytics (terodiline), dexfenfluramine and pergolide, antipsychotics (thioridazine), and quinolone antibiotics (grepafloxacine). ${ }^{47,48}$ Among 3D scaffold fabrication techniques, hydrogels, nanofibers, and decellularization have been widely used for tissue engineering of different organs $^{49-57}$ (Figure 3). But these techniques are successful for only avascular organs; however, development of artificial construct for highly vascularized organ like heart is very challenging. ${ }^{58}$ Branched blood arteries and capillaries offer additional complexity to fabricate functional cardiovascular organoids. Second challenge in engineering cardiac organoids is CM's limited self-renewal ability. Also, fabricating aligned and thick cardiovascular tissue is complicated as it 
Conventional 3D scaffolds tissue engineering techniques

A

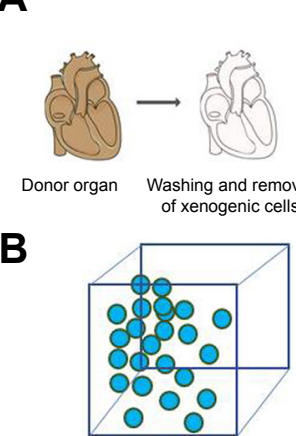

Nanogels

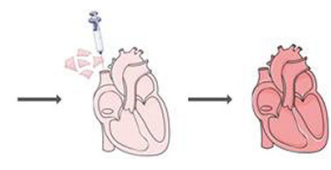

Seeding of host cells Functional organ

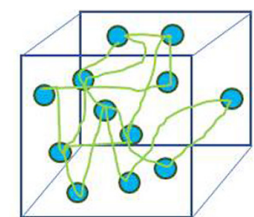

Hydrogels
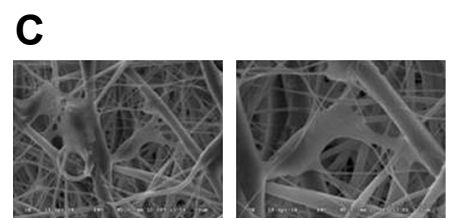

Nanofibers

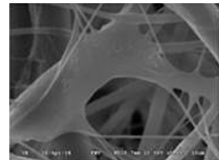

c.............
3D printed scaffolds tissue engineering techniques

D

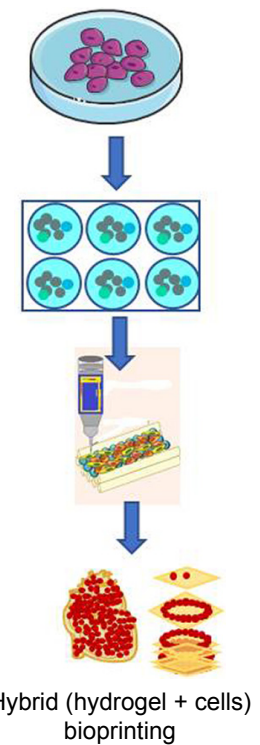

E

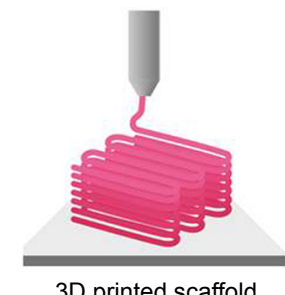

$\mathbf{F}$

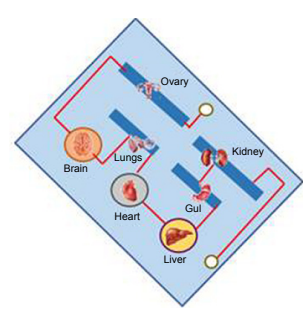

3D printed organ on chip

Figure 3 Comparison of conventional and modern 3D printed scaffold-based tissue engineering techniques: (A) decellularization, (B) hydrogels, (C) nanofibers, (D) spheroids and hydrogel hybrid bioprinting, (E) 3D scaffold printing, and (F) 3D printed microfluidics chip.

Abbreviation: 3D, three-dimensional.

requires microvascular network for exchange of materials and oxygen supply. Additionally, synchronization of synthesized tissue constructs with native tissue and execution of spontaneous contraction of construct is itself a challenge $\mathrm{e}^{24,59}$ (Figure 2). Due to these challenges, until now, idea of fully functional heart construction by using only conventional tissue engineering technique has not been achieved yet. Recently, 3D printing technique provided an alternative to make this possible, as 3D printing technique can develop a heterogeneous 3D scaffold with strong mechanical strength and with all required characteristics of an ideal scaffold for cardiac tissue engineering. ${ }^{44,60}$ With the advancement of 3D printing, scaffolds can now be fabricated with native ECM morphology and accuracy ${ }^{61}$ AutoCAD (computer-aided design) has made it possible to design whole 3D structure like an organ and then print it with biocompatible materials to get a 3D scaffold of organ shape. ${ }^{62}$ To develop an artificial organ or muscle patch, this scaffold must be seeded with tissue-specific cells. ${ }^{61,63}$ This technique enables us to use conventional 3D scaffolds (hydrogels) mix with cells (bio ink) and perform precise 3D bioprinting for organs by using different approaches ${ }^{63-66}$ (Figure 4, Table 1). In most recent strategies of $3 \mathrm{D}$ printing, organs are being printed directly by using spheroid without biomaterial scaffold involvement to avoid immune reaction. ${ }^{37,67,68}$ In this review, we discussed different 3D printed approaches for cardiac tissue engineering, microfluidics-based heart-on-a-chip technologies, scaffold free 3D bioprinting to develop an in vitro cardiac model for drug screening, ${ }^{69}$ and immune modulations for cardiac tissue engineering.

\section{D printing cardiac tissue engineering}

$3 \mathrm{D}$ printing is a technique in which materials are combined in 3D shape through computer-controlled process. ${ }^{63}$ There are different methods to complete this $3 \mathrm{D}$ printing process based on technology, cost, speed, resolution, and limitations ${ }^{70}$ (Figure 5). In case of 3D bioprinting, only a few of them have been used, primarily due to the restrictions made when working with biologic materials. ${ }^{71} 3 \mathrm{D}$ printing processes have two main categories: scaffold-based printing and scaffoldfree printing. ${ }^{72}$ Various approaches have been used for scaffold-based bioprinting: first fabrication of 3D scaffold by biomaterial(s) and the cell seeding; preprinting of scaffold and then cell layers printing or simultaneous printing of biomaterials and cells. In second scaffold-free category, bioink consists of individual cells or tissue spheroids are used for direct printing on substrate. ${ }^{73} 3 \mathrm{D}$ printing-based applications of tissue engineering in combination with stem cell technology have the potential to address the shortage of donor organs for transplantation and provide patient-specific tissue replacement. However, tissue vascularization and rapid 


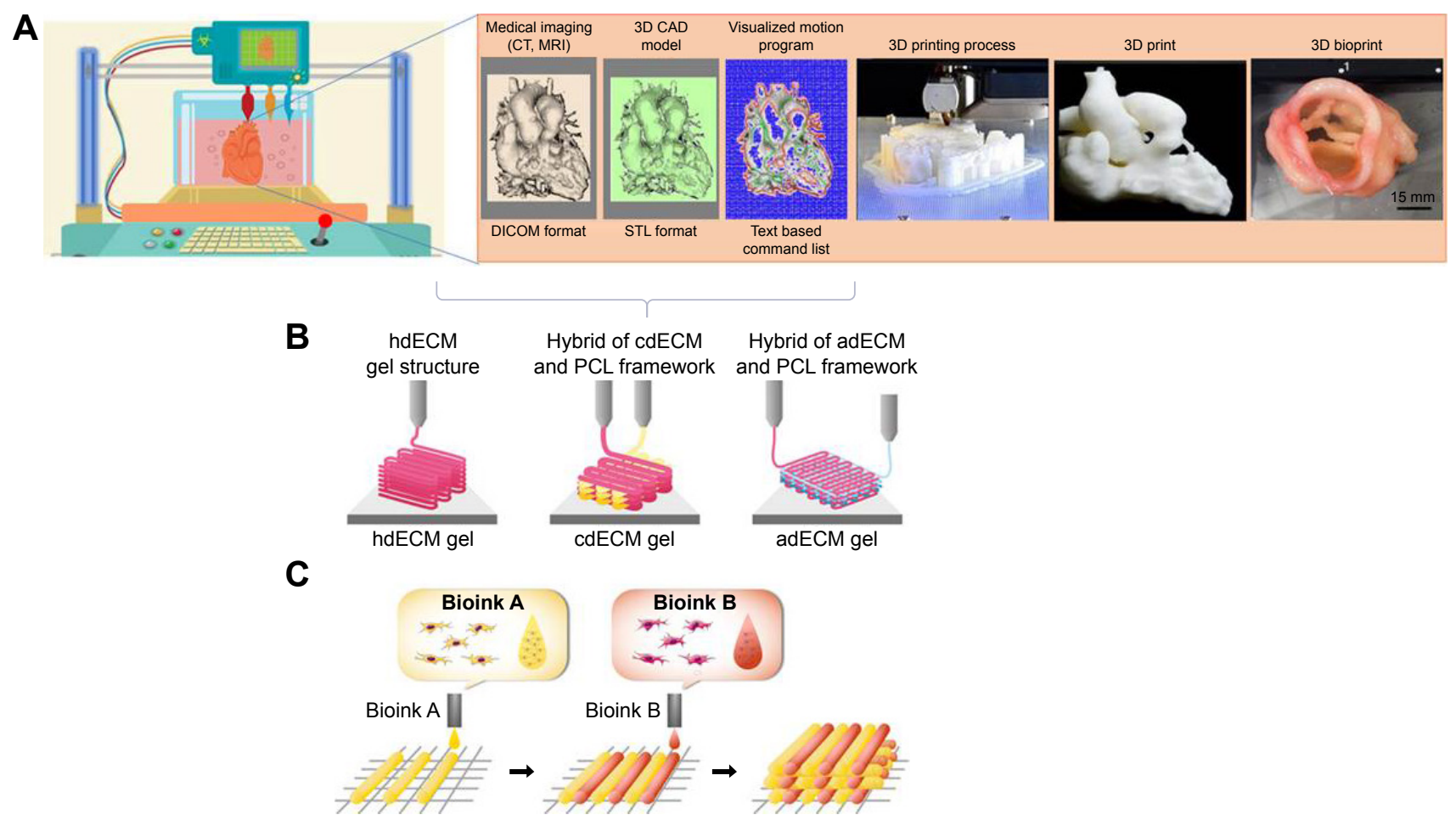

Figure 4 Process of 3D bioprinting, (A) steps of 3D bioprinting, (B) pre-scaffold fabrication bioprinting, (C) simultaneous hybrid 3D bioprinting.

Abbreviations: 3D, three-dimensional; CAD, computer-aided design; PCL, polycaprolactone; hdECM, heart decellularized-extracellular matrix; cdECM, cartilage decellularized-extracellular matrix; adECM, adipose decellularized-extracellular matrix.

vascular integration in vivo remain as two pervasive and long-standing obstacles. Here we will discuss few modern 3D printing approaches for cardiac tissue engineering.

\section{D printed scaffold tissue engineering}

One of the essential traits of an ideal scaffold is that it should have native ECM texture to support repair and regeneration process. 3D printing has offered a precise control to fabricate scaffold with native ECM morphology and through this it has prompted a tremendous excitement in tissue engineering. ${ }^{61}$ 3D printed scaffolds have defined geometric dimensions with fine 3D groove pattern composed of hybrid and heterogeneous materials to mimic the natural ECM morphology. Surface of 3D scaffold can also be patterned with channels to mimic additional function of endothelial network. ${ }^{74}$ These 3D patterns, grooves, and channels are key characteristics and they influence cell's migration, morphology, phenotype, and physiology. This phenomenon is called as topologic or surface guidance and it is important for stem cell differentiation into adipogenic, osteogenic, neurogenic, myogenic, and cardiomyogenic phenotype. ${ }^{75}$ To get control over cell physiology and limit their differentiation, composition and pattern of ECM are important to know and then replicate those key features with computer-aided software and design 3D printed scaffold with fine resolution. Until now a fine resolution of $\leq 1 \mu \mathrm{m}$ has been achieved to construct adjacent narrow channels. ${ }^{64,76}$ These narrow patterns also influence cell adhesions. For example in a recent study, a 3D printed scaffold seeded with CMs demonstrated synchronized movement just after 1 day of cell culture, which shows that individual cell adhesion with scaffold inside the microchannels was quick and interchannel coupling was also established quickly. ${ }^{60}$ Another study was conducted by using a novel multiphoton-excited 3D printing technique to print ECM-based scaffold with high resolution. They cultured $5 \times 10^{4}$ cells composed of human induced pluripotent cellderived cardiomyocytes (hiPSC-CMs), smooth muscle cells (SMCs), and ECs (in a 2:1:1 ratio) over this 3D scaffold to develop human cardiomyocyte patches (hCMP). The hCMP appeared soon after 24 hours of cell seeding and expressed the cardiac protein markers, calcium transients, and synchronized natural heart beating. The authors also used this scaffold to treat animal model of MI, and scaffold-free hCMP were used as control. This $3 \mathrm{D}$ printed scaffold-based hCMP showed improvement in heart physiology, infarct size, cell viability, endothelial density, and cell proliferation as compared to control. ${ }^{77}$ Recently, PCL and PCL carbon nanotube were used to develop 3D printed composite scaffolds and test 
Table I Scaffolds/materials used in 3D printing of cardiac and microvascular structures

\begin{tabular}{|c|c|c|c|c|}
\hline Materials & $\begin{array}{l}\text { Scaffold types/ } \\
\text { approach }\end{array}$ & Properties & $\begin{array}{l}\text { 3D printing } \\
\text { method }\end{array}$ & References \\
\hline PCL & Hydrogel/nanofibers & $\begin{array}{l}\text { Moderate mechanical strength. Biocompatible and } \\
\text { degraded easily }\end{array}$ & Inkjet/extrusion & $28,31,78$ \\
\hline PCL-CNT & Nanofibers & $\begin{array}{l}\text { High mechanical strength and electrical } \\
\text { conductance }\end{array}$ & Extrusion/laser & 78 \\
\hline PLGA & Hydrogel/nanofibers & $\begin{array}{l}\text { Brittle and relatively hard. Not good for tissue } \\
\text { remodeling. Biocompatible and biodegradable, } \\
\text { immunogenic }\end{array}$ & Droplet & 82,207 \\
\hline Gelatin & Hydrogel/cell layers & $\begin{array}{l}\text { Biocompatible, biodegradable, low cell adhesion } \\
\text { and viability. Good printability, high cell viability } \\
\text { and cross-linking agents. Low mechanical strength. } \\
\text { Immunogenic }\end{array}$ & $\begin{array}{l}\text { Extrusion/ } \\
\text { droplet }\end{array}$ & $81,102,130,131,148$ \\
\hline Chitosan & $\begin{array}{l}\text { Spheroids/hydrogel/ } \\
\text { nanofibers }\end{array}$ & $\begin{array}{l}\text { Biocompatible, biodegradable, immunogenic, } \\
\text { high cell proliferation and cell remodeling, low } \\
\text { mechanical strength, and antibacterial }\end{array}$ & Extrusion/laser & $32,50,55,86$ \\
\hline Fibrin & $\begin{array}{l}\text { Hydrogel/nanofibers/ } \\
\text { cell sheets }\end{array}$ & $\begin{array}{l}\text { High cell adhesion and viability, quick gelation } \\
\text { and low printability, biocompatibility, low } \\
\text { mechanical strength, good cell migration, and } \\
\text { vascularization }\end{array}$ & Extrusion & $\begin{array}{l}\text { I3I, I34, I35, I44, } \\
147,208\end{array}$ \\
\hline Alginate & Hydrogel/microdroplet & $\begin{array}{l}\text { Biocompatible, biodegradable, sustained release, } \\
\text { adoptable mechanical strength with cell growth, } \\
\text { rapid gelation, low cell adhesion, can be increased } \\
\text { by surface modification with collagen type I }\end{array}$ & $\begin{array}{l}\text { Extrusion/ } \\
\text { droplet }\end{array}$ & $83,127,148$ \\
\hline $\begin{array}{l}\text { Hyaluronic acid } \\
\text { Hyaluronic } \\
\text { acid/gelatin }\end{array}$ & Hydrogel & $\begin{array}{l}\text { Biocompatible, biodegradable, low mechanical } \\
\text { strength, high cell proliferation and viability, high } \\
\text { printability }\end{array}$ & Extrusion/inkjet & 102 \\
\hline $\begin{array}{l}\text { Decellularized } \\
\text { extracellular matrix } \\
\text { reinforced with PCL } \\
\text { framework }\end{array}$ & Hydrogel & $\begin{array}{l}\text { High cell viability, high cell adhesion, and } \\
\text { maturation. Easily synchronized with grafted } \\
\text { tissues, good printability, and mechanical strength. } \\
\text { No immune reaction. Biocompatible }\end{array}$ & $\begin{array}{l}\text { Extrusion/ } \\
\text { droplet }\end{array}$ & $56,57,149,150$ \\
\hline Collagen & Hydrogel & $\begin{array}{l}\text { High biocompatibility, biodegradable, high } \\
\text { cell adhesion, and cell remodeling. Has high } \\
\text { printability and acts as signal transducer and good } \\
\text { in electromechanical coupling with host tissues }\end{array}$ & $\begin{array}{l}\text { Extrusion/ } \\
\text { droplet }\end{array}$ & $29,76,134$ \\
\hline NIPAM & $\begin{array}{l}\text { Hydrogel/nanofibers/ } \\
\text { cell sheets }\end{array}$ & $\begin{array}{l}\text { Thermosensitive, sustained release, } \\
\text { biocompatible, can be made biodegradable, low } \\
\text { mechanical strength, can be modified easily with } \\
\text { various functional groups }\end{array}$ & Laser & 29,35 \\
\hline Poly(ethylene glycol) & Hydrogel & $\begin{array}{l}\text { Biocompatible, biodegradable, poor cell adhesion } \\
\text { and proliferation, moderate mechanical strength, } \\
\text { low printability, can be modified with various } \\
\text { functional groups }\end{array}$ & Extrusion & 83 \\
\hline
\end{tabular}

Abbreviations: CNT, carbon nanotube; PCL, polycaprolactone; PLGA, poly(lactic-co-glycolic acid); NIPAM, N-isopropylacrylamide.

its biocompatibility to support cardiac tissue engineering. ${ }^{78}$ Similarly, PLGA were used to construct 3D scaffold for tissue engineering applications ${ }^{79}$ (Table 1).

In a latest technique of $3 \mathrm{D}$ scaffold-based printing, a bioink composed of cells and desired biomaterials is directly used to print a scaffold in the shape of organ to develop full or partial organ (Figure 3). Recently, Zhang et al used the composite bioink consisting of ECs and microfibrous hydrogel in 3D printing to fabricate myocardium. During direct 3D printing, gravity and difference in density helped ECs to align themselves along the periphery of microfibers and form a symmetrical layer of confluent endothelium. Further, endothelium was overlayered by CMs with controlled anisotropy to develop a functional myocardium. This myocardium expressed the rhythmic beating. The authors also used this myocardium model with microfluidics-based 


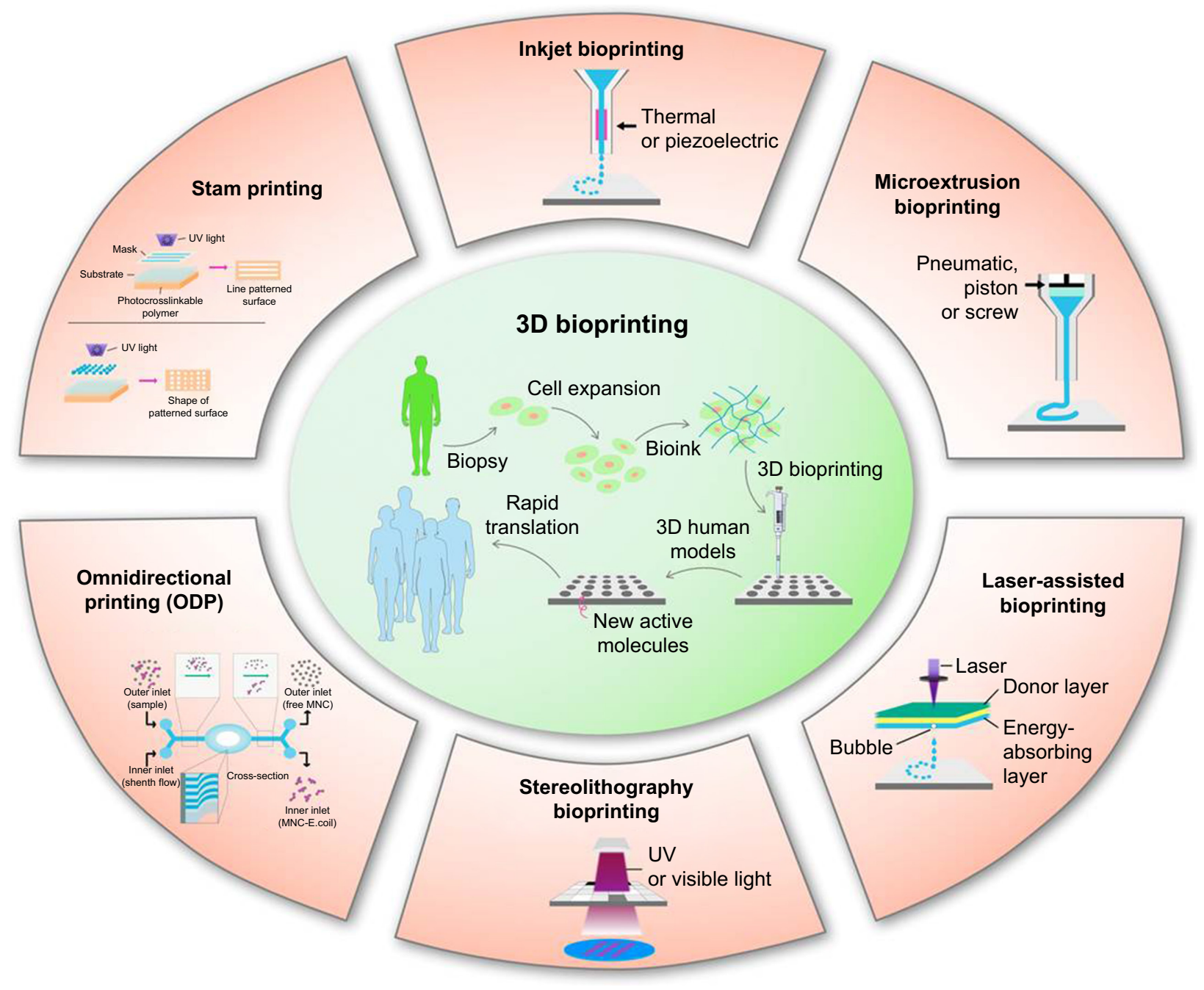

Figure 5 3D bioprinting technology and its types.

Abbreviations: 3D, three-dimensional; UV, ultraviolet.

perfusion bioreactor to develop endothelialized-myocardiumon-a-chip model for drug screening. It has shown that $\mathrm{CMs}$ derived from iPSCs can be used for developing endothelialized human myocardium. ${ }^{64}$ Recently the 3D sacrificial molding-based 3D bioprinting was introduced, and in this technique a rigid 3D lattice of sugar filaments was embedded with cells patterned over hydrogels. On contact with aqueous phase, sugar filaments subsequently dissolved and formed a microchannel network to support microvascularization. Though this is a simple method to introduce hallow channel network in hydrogels, hydrogel does not support lumen network when extensive remodeling of ECM happened with cell seeding. For instance, macroscopic, tissue contraction of heart muscle would be virtually impossible to establish without tight cell-cell connections at physiologic cell density. ${ }^{80}$ In another similar study, microchannels were fabricated in a 3D printed gelatin hydrogel cross-linked with an enzyme mTgase. These microchannels were used to align hMSCs and increase their differentiation into CMs. These microchannels also increased the CM functionality and orientation..$^{81}$ To 3D print fully functional cardiac tissue, a hybrid hydrogel system composed of sacrificial hydrogel, cell-laden hydrogel, and PCL was developed. They used these hydrogels along with $10 \times 10^{6}$ cells $/ \mathrm{mL}$ as a bioink to print a 3D cardiac construct at $18^{\circ} \mathrm{C}$. Separate dispensing modules were used for each type of hydrogel and PCL for 3D printing. Thus, the obtained cardiac tissue constructs showed a spontaneous synchronized beating in culture, showing potential for in vitro cardiac tissue development and maturation. Fully functional cardiac tissue development was confirmed by immunostaining of $\alpha$-actinin and connexin 43 . They also tested these bioprinted cardiac tissues for in vitro drug screening studies and their response was phenomenal and comparable to native cardiac tissues ${ }^{44}$ Similarly, albumin 
electrospun nanofibers were 3D laser patterned to develop grooves on its surface to align CMs. The authors seeded these patterned groves with ECs to form closed lumens in another layer of 3D patterned nanofiber. They also fabricated 3D cage-like pattern to attach PLGA microparticulate systems for sustained release of VEGF to promote vascularization, or dexamethasone, an anti-inflammatory agent. They grew these layers separately until they glued them with ECM-based biologic glue to form thick $3 \mathrm{D}$ cardiac patches and implanted them in rat and their coupling was observed. ${ }^{82}$ Maiullari et al used a bioink composed of alginate and PEG-fibrinogen (PF) hydrogel and human umbilical vein endothelial cells (HUVECs) and induced pluripotent cell-derived cardiomyocytes (iPSC-CMs) to develop functional construct in hydrogel strands produced through 3D printed microfluidics channels. They developed a functional cardiac construct with a high orientation index imposed by the different defined geometries and blood vessel-like shapes generated by HUVECs. They also demonstrated its in vivo grafting and integration of the engineered cardiac tissue with host's vasculature. ${ }^{83}$ All these scaffold-based 3D printed heart constructs' success depends on their electrical coupling with the native cardiac tissues, and in the future such 3D printed scaffold should have electrical conductance properties to facilitate the cell bundle extension to establish that connection.

\section{Cell types}

There are various types of cell used in 3D printed scaffolds or 3D bioprinting for cardiac tissue engineering. Mainly they are classified as nonhuman cells and human cells. They are either used as in single form or in mixture form. Rat myoblast cells have been shown to differentiate into functioning cardiac tissue in a variety of experiments. ${ }^{84}$ Among human cells, so far bone marrow- or adipose-derived stem cells, ESCs, and skeletal myoblast and resident cardiac stem cells are commonly used for cardiac tissue engineering application. ${ }^{12,32,42,85-87}$ With the advancement of stem cell biology, progenitor cells of different sources have also been now used in regenerative medicine for cardiac repair. Regenerative medicine and stem cell engineering are emerging as a promising solution to treat CVDs. ${ }^{8-90}$ ESCs are considered ideal for cardiac tissue engineering prior to their pluripotency and self-renewal. They are isolated from human blastocyst and cultured in vitro for the first time in $1998 .{ }^{91}$ Stem cell advancement resolved this issue of cell demand by generating iPSCs from somatic cells of patients. These cells can generate unlimited numbers of different types of cells including functional CMs just like ESCs. Somatic cells are reprogrammed into iPSCs through addition of transcription factors $k f-4, M y c$ c, Oct 4, and Sox $2 .^{92}$ When these iPSCs are further provided with transcription factors $F l k 1$, Isll, or $N k x 2.5$ they differentiate into cardiac progenitor cells, which are further used in cardiac tissue engineering. ${ }^{93}$ Furthermore, ESCs and iPSCs can also be differentiated into CMs and vascular cells through Wnt/Catenin signaling pathway. Wnt/Catenin signaling pathway can be activated by blocking glycogen synthase kinase 3 before the differentiation of ESCs and iPSCs. ${ }^{94,95}$ As these iPSCs will be derived from the somatic cells of the patient to be treated, they do not face immune problems. Thus, iPSCs are considered an important source to produce the autologous CMs needed to develop synthetic cardiac tissue construct. ${ }^{36,96,97}$ There are different protocols that have been developed to differentiate ESCs and iPSCs into CMs and are widely applied in tissue engineering to repair MI. However, immaturity of stem cell-derived CMs, due to incomplete maturation, ${ }^{98}$ remains a major obstacle, and promoting CM maturation is important in order to achieve the final goal of cardiac regeneration. ${ }^{99}$ Chong et al observed in a nonhuman primate model of myocardial ischemia-reperfusion that treatment with human embryonic stem cell-derived cardiomyocytes (hESC-CMs) led to significant remuscularization, albeit with nonfatal ventricular arrhythmias, due to incomplete maturation of hESC-CMs. ${ }^{100}$ Recently mouse somatic cells were programmed into pluripotent stem cells and further differentiated into electrophysiologic functional mature CMs expressing cardiac markers with the potential to treat MI. In terms of human cells, ${ }^{101}$ hCMPCs and hiPSC-CMs are popular choices for 3D bioprinting. ${ }^{102-104}$ These cells demonstrated genetic profiles and protein expression of native myocardium when bioprinted in the methods described above.

\section{Microfluidics-based 3D cardiac tissue engineering}

As discussed previously, one of the vital barriers in heart tissue engineering is the supply of oxygen and nutrients to thick cardiac tissue $(>100-200 \mu \mathrm{m})$ (Figure 2). Therefore, developing a perusable microvascular network, which mimics the natural vascular network of arteries, is a fundamental requirement to treat ischemic diseases. Previously, efforts were made to develop microvascular structures by stimulation of angiogenesis in vivo, by implantation of ECs, or by re-endothelialization of decellularized organs (Figure 3). But all these previous methods have shown their own limitations. Most recent development to resolve this issue is microfluidics devices, which mimic the complex 
microvascular tissue engineering and demonstrated the physiologic function of heart on the chip. ${ }^{64}$ Microfluidics devices involve microfabrication of the device through computer-aided designing, and electrical and mechanical control of fluid controls with 3D coating of biomaterials. ${ }^{105}$ Microfluidics devices like organ-on-a-chip and lab-on-a-chip could be a potential technique to implement key features of functional tissue units at the microscale and nanoscale levels. These systems presented the platform to observe a real-time effect of biochemical, mechanical, and electrical stimulations on new heart tissue constructs, which are key factors to improve tissue functions. ${ }^{25}$ As the functions of cardiac muscles are mainly determined by the $3 \mathrm{D}$ arrangement of their muscles' fibers and their perfect contractions in response to electrical impulse, microfluidics devices are one such approach to mimic such complicated arrangements of cardiac tissues in vitro to study the pathophysiologic nature of CMs and drug screening for cardiac toxicity evaluation.

A group of scientists used the microfluidics-based system to study the physiology of cardiac ventricle contractions under physical and electrical stimulation. To mimic the laminar anisotropic nature of cardiac ventricle wall, they fabricated 2D muscular thin films (MTFs), engineered by culturing anisotropic muscular tissue on top of fibronectinpatterned flexible elastomeric cantilevers. They monitored the contractile pattern of MTFs and compared it with sarcomere organization of the cardiac ventricle wall. They concluded that a high degree of 2D arrangements results in higher systolic and diastolic status. In addition to this, they controlled the fluid flow through a platinum pacemaker to analyze more thoroughly contractility tests and study MTF response to electrical impulse. Further, they also used their system for drug screening applications. They successfully demonstrated that $\mathrm{CMs}$ can produce relevant contractile forces in measurable range when cells are grown and molded in a 2D structure and under electrical impulse. ${ }^{106}$ Similarly, Kitamori group demonstrated artificial heart beating on chip through microfluidics by developing a bio-micro-actuator cultured with CMs to bend polydimethylsiloxane (PDMS) micropillars. They also developed a heart-on-a-chip pump, by using mechanical forces produced by CMs that aligned the cell sheet to pump fluids through microfluidic channels. ${ }^{107}$

To mimic the physiologic functions and protein expression of adult heart tissues, Sheehy et al fabricated an in vitro model of heart-on-the-chip. They seeded this chip with CMs and they showed that anisotropic engineered myocardium expressed a similar degree of global sarcomere alignment, contractile stress output, and inotropic concentration response to the adrenergic agonist isoproterenol. This engineered myocardium also expressed the myofibril-related gene expression similar to muscle fibers isolated from the ventricular tissue of adult rat. ${ }^{108}$

\section{In vitro 3D microfluidics functional heart models for drug screening}

The common strategy to treat CVDs is to use therapeutic interventions that mitigate symptoms; however, these treatments are not sufficient for full recovery and patients are left only with transplant option. To improve medical care options, development of new drugs must be considered. Drug discovery is a complex and time-consuming process involving significant basic research and preclinical evaluation before testing in patients for drug cytotoxicity and clinical efficacy. ${ }^{109}$ In conventional drug screening approaches, to evaluate a drug for its ADME (absorption, distribution, metabolism, elimination) and cytotoxicity, animal models are being used as disease models (Figure 6). Preclinical studies conducted on animal models often fail in human trials and lead to huge economic loss along with adverse effect on human lives. Drug-induced cardiotoxicity is one of the major issues for drug industry working on new therapeutics research for CVDs. ${ }^{110}$ Over the last 15 years, almost $20 \%$ of drugs were called back from market due to their cardiotoxicity issues. In addition to them, many of the drugs showed unwanted lethal effects during clinical trials after they passed animals trials. Approximate cost for one drug to pass through clinical trials is around 3-4 billion USD. This indicates that the failure of one drug causes a huge economic loss to drug manufacturing company or funding agency. In the last two decades, almost 50 drugs have been called back from market due to cardiotoxicity.

The main reason behind this huge economic loss and time loss is the lack of proper in vitro and in vivo drug testing assays to evaluate drug toxicity, which mimics the exact microenvironment with natural human body environment. Animal-based in vivo models have many ethical concerns, require time-consuming procedures, are expensive, and require sophisticated animal housing. Most important results with animal models are not reliable because physiology of human organ and its chemical interaction with the human body is different from the animal's body. Though 2D-based static cell culture dishes used for in vitro drug screening assays are physiologically relevant, modeling vascular system specifically for primary perfusion and pharmacokinetic interface as ECs cultured in the absence of hemodynamic stresses (stretch, shear, and pressure) does not mimic 
Conventional methods of drug screening

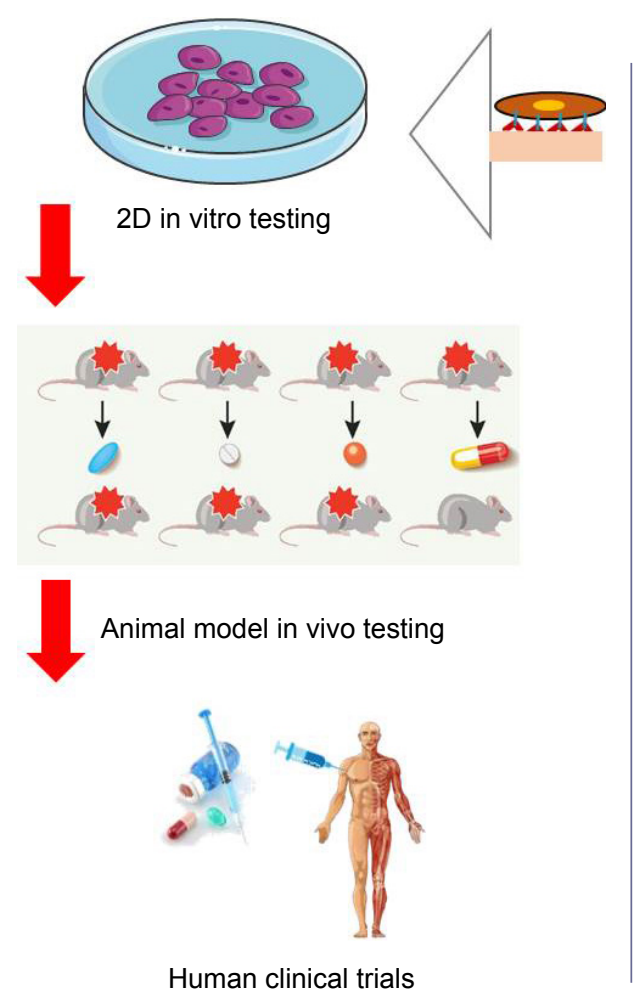

Tissue engineering-based drug screening

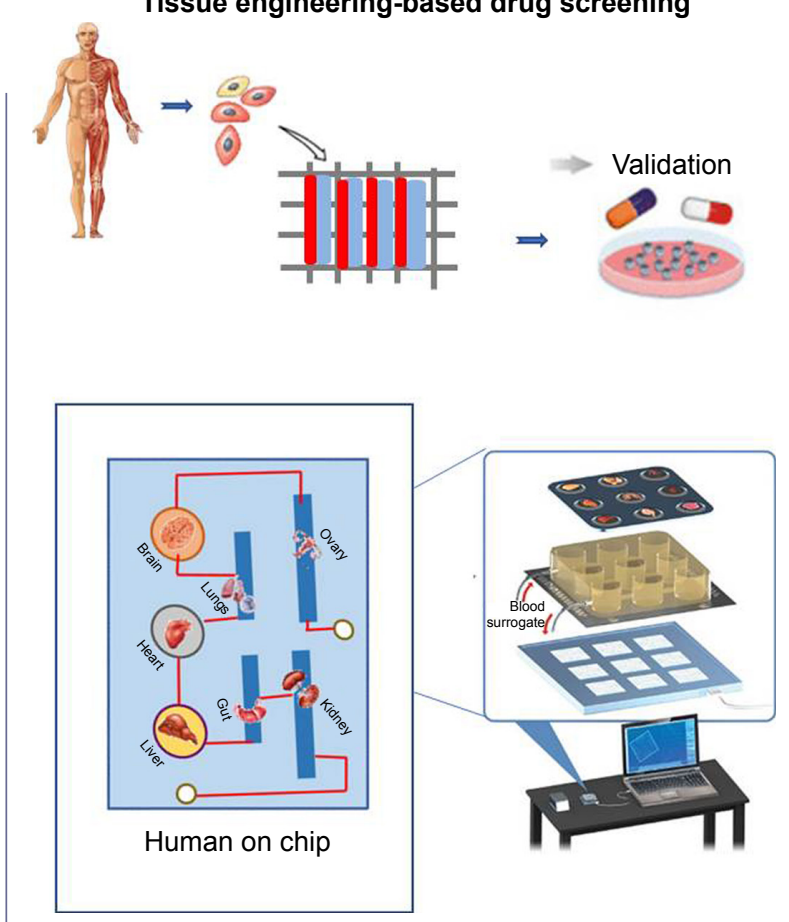

Figure 6 Conventional vs 3D microfluidics-based drug screening model for cardiotoxicity testing.

Abbreviation: 3D, three-dimensional.

the natural physiology of organ or tissues. Therefore, such assay models are not able to predict natural human body response to the drugs.

Advancement in biomedical engineering has presented a new 3D microfluidic-based approach as an alternative in vitro model to resolve this complex issue of drug screening (Figure 6). In addition, integration of bioengineering technologies with 3D printing technologies further extended this microfluidics platform to develop heart-on-a-chip model to mimic the biology and physiology of fully functional heart. Moreover, to replace human clinical trial, a further extended platform with assemblies of different organs on chip to demonstrate human-on-a-chip provides a system to screen drugs, and its mechanism of actions and evaluate its ADME with respect to mutual interactions of different organs. As these platforms are seeded with the human cells in ECM like natural 3D microenvironment, their results are more reliable for human applications. Microfluidics devices that demonstrate the heart model integrated with endothelial and vascular system can predict drug cardiotoxicity better than animal model. Recently, to depict such a system, cardiopatch $3 \mathrm{D}$ culture platform was developed to evaluate drug and disease modeling by using hiPSC-CMs. They developed this system to mimic highly mature and functional human heart (cardiopatch) with clinically active surface area of $4 \times 4 \mathrm{~cm}$. They set a free-floating dynamic culture with continuous nutrients supply and exchange of waste materials, and maintain cell seeding density to reflect highly accurate in vitro cardiac maturation model system. After 5 days of culture, hiPSC-CMs showed uniform sarcomere alignments showing I-bands, H-zone, and sketch of T-tubules and $\mathrm{M}$ bands. The cardiopatch showed spontaneous contractions, robust electromechanical coupling, and increased expression of maturation markers comparable to adult myocardium. This system can be scaled up to clinical dimensions for drug screening while preserving spatially uniform properties with high conduction velocities and contractile stresses. ${ }^{8}$ In another study, researcher used PDMS-based microfluidics system to evaluate electrical and mechanical properties of heart construct. They called this system I-Wire heart-on-a-chip. In this system, I-wire assay provided them with an ability to apply control over the electrical and mechanical stimulus to 3D embryonic cardiac constructs (ECTCs) and measure their impact on the constructs. A calibrated flexible probe provides strain load to the ECTC via lateral displacement, and the microscope noticed the deflections of both the probe and the 
ECTC. ${ }^{60}$ This system helped to study the behavior of cardiac tissues under controlled mechanical and electrical stimulus. Similarly, Marsanso et al used synchronized stimulus and translated the uniaxial cyclic strain in a 3D microfluidics model to mimic the mechanical stimulus faced by CMs in the native myocardium. Their device had an array of hanging posts, which restrict cell-laden gels and a pneumatic actuation system to produce uniaxial strains on the microengineered cardiac tissues ( $\mu$ ECTs). They evaluated the effect of physiologic cyclic uniaxial strains $(10 \%-15 \%)$ on the maturation and physiology of uniformly arranged $\mu$ ECTs developed by seeding neonatal rat or hiPSC-CMs using this device. They showed that cyclic uniaxial strain induced the maturation as well as improved the contraction and synchronized beating. They also tested the human $\mu$ ECTs for drug screening in physiologic environment. These tissues responded well to isoprenaline ( $\beta$-adrenergic stimulation) at low concentrations $(1 \mathrm{nM})$ with positive chronotropic effect when compared to the previously reported response concentration limit of $100 \mathrm{nM}$ and $1 \mu \mathrm{M}$ in large- and microscale human embryonic cells, respectively. This beating analysis of hiPSC-CM constructs under controlled administration of isoprenaline showed its potential applications for drug development and cardiotoxicity studies. Indeed, the ability to generate reproducible and functional cardiac microtissues from hiPSC-CMs broadens the application horizons of this device, with the possibility to generate patient-specific myocardium-like tissues, which can model unique and relevant genetic cardiac disorders. ${ }^{111}$

One of the main problems with cardiac tissue engineering using a 3D scaffold is building few millimeters thick cardiac tissue and supply of oxygen to CMs. Zhang et al reported a 3D microfluidics scaffold called AngioChip, which has extensive network of nanopore and microholes in the microfluidics channels to enhance their perfusions and intercellular communications. This AngioChip supports the assembly of parenchymal cells on a mechanically stable matrix surrounding 3D microfluidics network coated with ECs. They also demonstrated the vascularized cardiac tissues engineered using AngioChips to show drug delivery pattern clinically relevant to intravenous injection and presented that few millimeter-thick cardiac tissues can be developed in a scalable manner. Moreover, they implanted AngioChip cardiac tissues to rat hindlimb femoral vessel by direct surgical anastomosis to restore its blood perfusion. ${ }^{112}$

To present the microfluidics system as a heart disease model, Horton et al presented cardiac dysfunction model by using angiotensin II (ANG II). This heart-on-a-chip model composed of arrays of MTFs can help to differentiate the healthy and abnormal tissues by tracking the deflection of thin films that results from contraction. The ANG II was used to elicit pathologic responses and they measured the cardiac function by expression of cardiac markers, calcium transients, morphologic changes, and contractile stress after and before administration of ANG II. They also compared the results with already available experimental and clinical results and were found to have comparable results. They successfully demonstrated that the in vitro disease model can be used for drug screening applications. ${ }^{113}$ To evaluate the effect of microsystem's geometry and microenvironmental conditions on the morphology and functions of cardiac cells, Kobuszewska et al developed the microfluidics devices with various shapes and different physiologic conditions (static and dynamic). They developed longitudinal, circular, and parallel microfluidic chambers made of PDMS/glass with static and dynamic fluid flow. Rat cardiomyoblasts (H9C2) were seeded on the devices for testing purpose. They concluded that dynamic fluid flow influences the cell morphology, their alignment in fluid flow directions, proliferation, and maturation when compared to static conditions. This study supports the idea that microfluidics devices with dynamic fluid flow mimicked the natural environment necessary for proper growth of cardiac cells. ${ }^{114}$ Skardal et al fabricated an integrated three-tissue organ-on-a-chip platform consisting of tissues of heart, liver, and lungs to study interorgan interactions and drug response. They evaluated the pharmacokinetics of propranolol and epinephrine in clinically relevant concentrations to control the cardiac organoid beating rate. They also tested the effect of other drug molecules on this integrated organoids-on-a-chip model. ${ }^{115}$ All these 3D microfluidics models confirmed their future potential to replace currently available in vitro and animal-based in vivo models for drug development applications. Lind et al had presented a 3D printed microfluidics device, which continuously monitors electronic readout of the contractile stress of multiple laminar cardiac microtissues developed in 3D printed microfluidics channels. They used this device for maturation of HSCs-derived laminar cardiac tissue and also for screening of drug to study cardiotoxicity. This 3D printed microfluidics device successfully provides a platform to observe contractile behavior of cardiac tissues and drug screening in closed controlled microenvironment. ${ }^{116}$

\section{Bioreactors and 3D microfluidics hybrid system for cardiac tissue engineering}

Bioengineering has now reached to a level where it can successfully control and reproduce the actual environmental 
conditions for development, regeneration, and control of cells, while making possible real-time visualization into cellular and their morphogenic events. Unlike 3D tissue engineering approaches, which are not exactly similar to exact natural environment of the heart tissue, bioreactors are able to set a necessary balanced environment for biologic functions that are required for cardiac cell differentiations as well as their functional integration for myocardial tissue regeneration. ${ }^{117}$ The hybrid bioreactors approach is an advanced strategy in which scientists have used the microfluidics systems for nutrients perfusion and exchange of metabolites and gases, which are difficult to get managed only by cell diffusion in a few-millimeter-thick tissues. Previous studies have successfully shown that media perfusion through microfluidics has increased the cell survival rate in a few-millimeter-thick cardiac tissues. ${ }^{118,119}$ Radisic and her colleagues used this concept and developed a thicker and functional cardiac tissue through microfluidics perfusion system to supply oxygen to seeded cells. They also developed a 3D bioreactor-based scaffold with multiple parallel channels similar to capillary network to enhance perfusion of cells to match the nutrients demand. They also incorporated an oxygen carrier compound perfluorocarbon (PFC) to mimic the natural oxygen carrier molecule, hemoglobin, in the cell culture medium to fulfill oxygen demand of seeded cells in scaffold. They used this model to calculate total oxygen consumption and tried to find the relation between oxygen distribution in tissues and channel physical dimensions, flow rate, concentration of PFC, and cell density. ${ }^{120}$ This model provided foundation to investigate detailed insights for engineering of tissue with a specific thickness and cell density, and set the founding principles to mimic natural environment of cardiac muscles tissue engineering. In another similar study, Maidhof et al coupled electrical stimulations with microchannels perfusion bioreactors scaffolds for cardiac tissue engineering. The control of hydrodynamic shear stress due to flow of medium in microchannels and coupling of electrical stimulations enhanced the physiology of cardiac tissue construct. The author used this system to monitor the behaviors of CMs cultured in microchannels by measuring the lower thresholds limit for higher contraction amplitudes (indicative of functional contractile maturation), higher maximum capture rates (indicative of increased intracellular connections), and contractions (indicative of cellular electrical excitability). ${ }^{118}$

\section{Scaffold-free 3D bioprinting}

Despite success of scaffold for tissue engineering, still scaffolds offer problems like immune reaction and degradability.
In some cases, the adverse immune reaction by scaffold can be life threatening as it can damage or degenerate area under negative self-immune reaction. ${ }^{103,121}$ Therefore, scaffold-free $3 \mathrm{D}$ bioprinting has emerged as an alternative technique to fabricate artificial organ. ${ }^{61,63}$ In this 3D bioprinting, scaffold support is compensated through adhesion of cells. Various approaches have been introduced to achieve 3D bioprinting, which includes pellet culture, hanging drop, hydrodynamic cell trapping, spinning flask, liquid overlay, micromolding, and rotating wall vessel techniques. ${ }^{67,122-126}$ In all these techniques, cell are spread in 3D environment and their rapid differentiation term them into a solid mass due to cell-cell adhesion. Once cells are grown in specific shape they can be placed layer by layer with the support of $3 \mathrm{D}$ printer and seeded with other cells robotically to develop a tissue-like form. As in a recent study, alginate microdroplets were used to develop scaffold-free construct. These alginate microdroplets were deposited on calcinated substrate layer by layer into ring-shaped hydrogel molds and seeded with ECs and smooth muscles cells (1:1) robotically and toroid-shaped tissue was developed, which showed tissue morphology, cell-cell adhesion, and maturation. ${ }^{127}$ Use of scaffold or materials in bioink posed issues of biodegradability, immune reactions, and toxicities. To avoid these complications, Ong et al recently used 3D bioprinting technique for direct delivery of stem cells without addition of biomaterials. They used the mixture of hiPSC-CMs, fibroblast (FB), and ECs in the ratios CM:FB:EC $=70: 15: 15,70: 0: 30,45: 40: 15$ to create spheroids. They used these spheroids for $3 \mathrm{D}$ printing of cardiac patches. These patches started beating spontaneously within 3 days while they were still on the needle array, and the voids between the patches got fused in another two days resulting in a complete electrically integrated patch. Patches showed ventricular-like action potential waveforms and uniform alignment of cells and electrical conduction throughout the patch. As these 3D constructs lack presence of any external materials, the ECM of tissue was more natural, which supports the cell-cell interaction and electromechanical coupling. ${ }^{104}$

But mostly applied technique for 3D bioprinting is tissuespheroid-based organ bioprinting. Tissue spheroids are 3D well-organized mass of cells, when they are placed over each other in layers; due to surface tension and adhesion they fused into living material and this material reflects the exact similar properties from which the cells were isolated (Figure 3). They have the advantage to keep their characteristic of native tissue even after their assembly in large structure or organoids. ${ }^{67}$ Spheroids constituted by mixture of cells on their settlement 
differentiate into their native structures. Especially for cardiac tissue engineering, seeding of EC cells in CM spheroids showed network of microvascularization. Noguchi et al used tissue spheroids consisting of rat neonatal ventricular CMs, human dermal fibroblasts, and human coronary microartery ECs to construct as viable contractile cardiac patch. ${ }^{128}$ Similarly, Ong et al used spheroids composed of hiPSC-CMs, fibroblasts, and ECs to fabricate myocardial patches. ${ }^{104}$ This patch showed myocardium morphology with spontaneous contraction, ventricular-like action potential wave form, and uniform conduction band. Later, this path was grafted in vivo into a rodent model and it showed growth, development, vascularization, and synchronization with the native tissues. These 3D bioprinted constructs by using spheroid showed potential to develop fully functionalized heart or large tissue construct to treat MI.

\section{D bioprinting of cardiovasculature constructs}

Cardiac tissue engineering is directly influenced by angiogenesis or microcirculatory vessels as they are necessary for main nutrients demand and gaseous exchange. Therefore, 3D printing for cardiac tissue engineering involves multidisciplinary approaches and use of mixture of biomaterial, cells, and angiogenic factor as bioink. ${ }^{129}$ For neovascularization, angiogenic factors play an essential role and can modulate their migration, activate the progenitor (endothelial progenitor) cells and maturation, and promote self-assembly. ${ }^{39}$ As we discussed earlier, one of the critical challenges in large tissue construct is oxygen supply, while success of tissue construct based on vascularization to keep construct viable is by maintaining required supply of materials and oxygen. 3D bioprinting has emerged as a promising tool to address this challenge by presenting fully biomimetic tissue constructs and organs for clinical applications. The 3D bioprinted organ mimics the anatomical feature and physiology of native tissues and showed initial success with native vascularization. There are two approaches that are used for 3D printing of such vascular structure; one involves direct printing of tubular vessels and other is indirect printing of sacrifice materials (eg, gelatin or pluronic F127) mixed within hydrogel. ${ }^{130}$ Once the hydrogel scaffold solidifies and shrinks, it leaves a hollow vessel structure that is later seeded with HUVEC cells. ${ }^{130}$ This second method is known as microextrusion. This method is considered better as compared to direct printing due to its stable tubular structure and choice of broad range of sacrifice materials. But the vascular channels printed by this method have limitations of size and shape due to the nozzle features of 3D printer. Various studies have used this technique with a wide range of hydrogels known to respond less for cells (for example, migration, spreading, and viability) but with high mechanical stability, a factor important for cardiac tissue engineering. ${ }^{131-133}$ Hinton et al used native materials like fibrin and collagen, which are difficult to handle with extrusion-based system for vascular structure printing. ${ }^{134}$ Maiullari et al used PF-based scaffolds for developing a 3D cardiac tissue composed of iPSC-derived CMs with a high orientation index imposed by the different defined geometries and blood vessel-like shapes generated by HUVECs and they implanted in vivo subcutaneously in NOD-SCID mice, which demonstrated the integration of the engineered cardiac tissue with host's vasculature. ${ }^{83}$

On the other hand, microvalve-based bioprinting technique makes it easy to use materials with low viscosities such as fibrinogen or gelatin $(<5 \% \mathrm{w} / \mathrm{v})$ for $3 \mathrm{D}$ printing with better resolution compared to extrusion-based techniques and enhanced cell viability. ${ }^{131,135}$ The stereolithographic and laser assistance in this technique helps to achieve high resolutions and channels with typical diameters of only a few micrometers to about $125 \mu \mathrm{m}$ being attained. ${ }^{136}$ But this technique did not incorporate cells from the first point of printing. To get cellularized vessel structure photocrosslinkable patterning technique is used; in this method, hydrogels are precisely deposited to form an autonomous vessel structure. ${ }^{130,136}$ Printing of a thick vascularized tissue $(>1 \mathrm{~cm})$ with these 3D bioprinting approaches has been reported, which has also shown high cell viability for 5 weeks. ${ }^{137,138}$ The $3 \mathrm{D}$ bioprinted vascular channels were mostly designed and printed as hollow tubes with a diameter ranging from a few hundred micrometers ${ }^{139-141}$ up to the millimeter range ${ }^{61,130}$ with their inner wall deposited by a single layer of ECs. But the double-layered vascular cell deposition is possible with specific pattern using the multicellular cylinders consisting of two different types of cells, for example human skin fibroblast and human SMCs. This dual-layer patterning is used to develop vascular structures of distinct hierarchical trees and shapes. ${ }^{142}$ This layer-by-layer deposition of hydrogels and cell mixture of mouse embryonic fibroblast has been used to bioprint an aortic tissue construct. ${ }^{143}$ Similarly Xiaofeng et al used composition of fibrin and microvascular ECs as bioink for the 3D printing of microvasculature. ${ }^{144}$ In another study, Fukunishi et al used biodegradable scaffold with autologous cells for 3D printing of vascular conduits and planted it in the inferior vena cavae (IVC) of sheep. After 6 months of implant they explanted the graft and it showed complete dissolution of scaffold and left behind conduit with native IVC tissue 
morphology. ${ }^{145}$ Schöneberg et al printed the in vitro blood vessel by using mechanical microvalve inkjet 3D printer. This blood vessel system possesses fibrous and collagenous matrix of normal human dermal fibroblasts (NHDFs) in the outer surface to mimic the adventitia, a human umbilical artery SMC layer to replace the media and a continuous endothelium (HUVEC) imitating the intima. ${ }^{146}$ Similarly, a natural mimic artery ring was developed by seeding the human aortic smooth muscle cells (HASMCs) on 3D printed tubular fibrin hydrogel. ${ }^{147}$ The alginate-gelatin solution was used by Liu et al to print artificial vessel construct by using rotating rod. ${ }^{148}$ Decellularized ECM with stem cells has been reported as bioink for 3D printing of prevascularized functional cardiac construct. ${ }^{149,150}$ Scaffold-free 3D printing approach has also been used to develop microvasculature structure for cardiac tissue engineering as suction and deposition of multicellular spheroids on a needle array used to print tubular structure. ${ }^{151}$ Approximately 500 multicellular spheroids composed of NHDFs (50\%), HUVECs (40\%), and HASMCs (10\%) were used to develop this tubular structure by $3 \mathrm{D}$ printer and it is perfused for 1 week before implantation into the abdominal aortas of F344 nude rats for 5 days. This tubular graft performance was monitored by ultrasonography and histologic examinations to observe fluid flow after 2-day interval. Remodeling of the tubular tissues (enlargement of the lumen area and thinning of the wall) observed along with assembly of ECs lining the lumen was also confirmed 5 days after implantation. To develop an ideal blood vessel construct, different theoretical models were also proposed to reach native morphology and physiology of blood vessels. These theoretical models consider different parameters like nozzle speed, motor speed, extrusion speed, bioink concentration, viscosity, mechanical properties, and printer speed. ${ }^{152} 3 \mathrm{D}$ printings of the microvasculatures are one of the key areas of future research to address CVD burden. To explore more self-degrading materials with analogous mechanical properties, computational or mathematical modeling is required to achieve fully functional vessel construct.

\section{Applications of 3D printing in CVDs}

$3 \mathrm{D}$ printing has played a vital role in understanding anatomy, physiology, heart diseases, cardiac masses, electrophysiology, and bioprinting. It has been used in the diagnosis and treatment of valvular heart disease. The 3D printing helps in undermining the aortic anatomy including aortic valve area, root morphology, calcium distribution, and distance to coronary arteries in aortic stenosis. ${ }^{153-155} 3 \mathrm{D}$ printed functional models of aortic valves have been helping to understand blood flow across the aortic valve. ${ }^{156,157}$ The 3D models of the aorta precisely mimic the aortic anatomy and can be linked to flow loops to increase physiologic simulation. ${ }^{158,159}$ Deployment of transcatheter aortic valve replacement (TAVR) is also evaluated by these models to observe their alignment in the presence of severe tortuosity or concomitant mitral valve prosthesis to avoid any obstacle or complication. ${ }^{160,161}$ Further, TAVR choice (size of annulus, valve type) prediction of future possible leakage of paravalvular and prior planning of its percutaneous closure can be optimized. ${ }^{153-155}$ Similarly, mitral valve $3 \mathrm{D}$ printed functional and static models are used to know the etiology of mitral valve-associates diseases and understanding of blood flow under various loading conditions. ${ }^{162-164} 3 \mathrm{D}$ printed models are also helping in planning of surgical procedures as in the case of septal myectomy of left ventricular structure. ${ }^{165-169}$ Such preplanning of surgery can improve postsurgery blood flow for complex repairs as in the case of Nikaidoh surgery in patients with transposition of the great arteries associated with interventricular communication and outflow tract obstruction. ${ }^{170}$ They are also used in device/stent selection and their optimum positioning to avoid branch vessel obstruction. ${ }^{171,172}$ Moreover, Tam et al showed that the use of 3D models in procedural planning of complex abdominal aortic aneurysms led to change in endovascular approach in $20 \%$ of cases. ${ }^{173}$

The $3 \mathrm{D}$ printed model has applications in diagnosis of heart diseases and helps in better understanding anatomical correlation in congenital heart problems, such as complex ventricular septal and double outlet right ventricles defects as compared to common imaging. ${ }^{174,175}$ These models for congenital hearts defects facilitate the surgical planning and they are precise as compared to surgical finding to plan optimal baffle orientation. ${ }^{175}$ Through their accurate demonstration of targeted anatomy of congenital heart defects these 3D models increase the confidence level of the specialist for operative procedures, which was never attained with $3 \mathrm{D}$ imaging techniques.

Other than 3D printed applications in treatment and diagnostics of CVDs, these models are also used as educational and communication instruments. They are effective in enhancing the understanding of spatial relationship of congenital heart diseases among students. ${ }^{176-179}$ Students' score and their retention rate in medical exams have also shown improvement when they receive demonstration with $3 \mathrm{D}$ printed models. ${ }^{180}$ Further, impact of understanding among students with 3D printed model-based lessons is comparably similar to cadavers, ${ }^{181}$ while cadavers involve many ethical and financial concerns. ${ }^{182-185}$ Bench-top functional flow 
cardiac models are also helping in getting basic knowledge of valvular and coronary artery hemodynamics. ${ }^{156,186}$ Advanced 3D printed models are setting new horizon of advanced medical education as they have reflected the native tissue properties under ultrasound as compared to real-time imaging; therefore they can be applied for echocardiography simulation. ${ }^{187}$ This advanced use of $3 \mathrm{D}$ heart models is very helpful and relevant for teaching congenital diseases as it demonstrates full spectrum of the problem and the variations that may exist even with a single condition. 3D models provide students with opportunity to have sight and touch experience to achieve rapid understanding of anatomical defects, including complex conditions such as criss-cross atrioventricular connections. Beyond the teaching of medical students and staff, 3D printed models are also helpful in communication with patients. Patients can now understand better about their disease and surgical treatments. As a result of this they feel confident and comfortable for providing informed consent and their engagement in shared decision making for operative procedures. ${ }^{188}$ 3D models were also used in multidisciplinary rounds in the intensive care unit to explain treatment plans in complex patients. ${ }^{189}$ Through this wide range of applications 3D printing technology will help us to further understand the complications and finding new treatments for CVDs.

\section{Foreign body reaction and immunomodulation in cardiac tissue engineering}

Any implant faces foreign body immune reaction, and dealing with this reaction is important for successful synchronization and sustainability of 3D implant or tissue construct. During the first contact of the 3D scaffolds with tissue, proteins from body fluids get adsorbed on the surface of the implant. This adsorption of proteins further activates the coagulation cascade and inflammatory response to material. ${ }^{3,4}$ These protein layers also include ECM proteins like collagen, fibronectin, and vitronectin, and they mainly regulate the inflammatory response. ${ }^{190}$ Other than adhesion receptors, danger signals also known as alarmins also activate white blood cells and enhance inflammatory response to the implant. ${ }^{191}$ Alarmins are analogs of pathogen-associated molecular patterns and include heat shock proteins, high mobility group box 1 (HMGB1), ATP, and uric acid. Through these immune players soon after protein adsorption inflammatory cells mainly polymorphonuclear leukocytes (granulocytes) migrate to implant and act as the first line of defense. If this inflammatory response persists, it acts as a driving force to intensify the immune response. Monocytes that reach at the implantation site undergo a phenotypic change differentiating to macrophages and secrete chemokines like IL-8, MCP-1, and MIP-1b to spread message. ${ }^{192}$ These macrophages attached over the surface of the implant start secreting phenotypically inflammatory cytokines, ROS, and degenerative enzymes and displaying high phagocytic capacity. The cytokines IL-4 and IL-13 have been identified to induce macrophage fusion on biomaterial surfaces in vivo and in vitro. ${ }^{193}$ Then the phagocyte-specific phenomenon referred to as frustrated phagocytosis starts. All these immune reactions result in inflammations and in severe cases they lead to infection and there is a need to remove the implant. Therefore, scientists are trying to modulate this foreign body reaction to make implant more biocompatible by introducing less immunogenic materials.

Recent research in the understanding of body's immunologic reactions associated with tissue repairs in MI and other tissue damages has given an impetus on the role of immunomodulation in regenerative medicine. ${ }^{194-197}$ There occur cascades of immune reactions during an injury in a tissue (Figure 7), which slowly resolves in a week or 10 days completing its repair process. ${ }^{197}$ Innate immune system initiates this process, wherein neutrophils followed by monocytes/macrophages are recruited. These are subsequently accompanied by recruitment of $\mathrm{T}$ cells and other immune cells. Neutrophils that are recruited first perform phagocytosis with the help of neutrophil extracellular traps. They also help in the recruitment of macrophages and monocytes, which clear off the dying neutrophils and other cellular debris, thus initiating the resolution of inflammation. Macrophages, both the resident as well as newly recruited ones, have a profound role in tissue healing by secretion of proteases, cytokines, growth factors, ECM components, and other soluble mediators promoting tissue repair, fibrosis, or regeneration. These macrophages in the later stage of tissue repair process can take up either a proinflammatory (M1) path or an anti-inflammatory (M2) path based on their cell-cell communication and their microenvironment. The M2 macrophages produce wound healing factors like arginase, ECM components, and growth factors such as VEGF-A, plateletderived growth factor, and insulin-like growth factor (IGF). The dendritic cells regulate the tissue repair/regeneration process by controlling the recruitment of macrophages. On the other hand, certain T cells (Tregs and $\alpha \gamma \mathrm{T}$ cells) also have regulatory functions, such that they regulate the expression of few factors like arginase, anti-inflammatory cytokines like IL-10, TGF- $\beta$, amphiregulin, growth factors, 


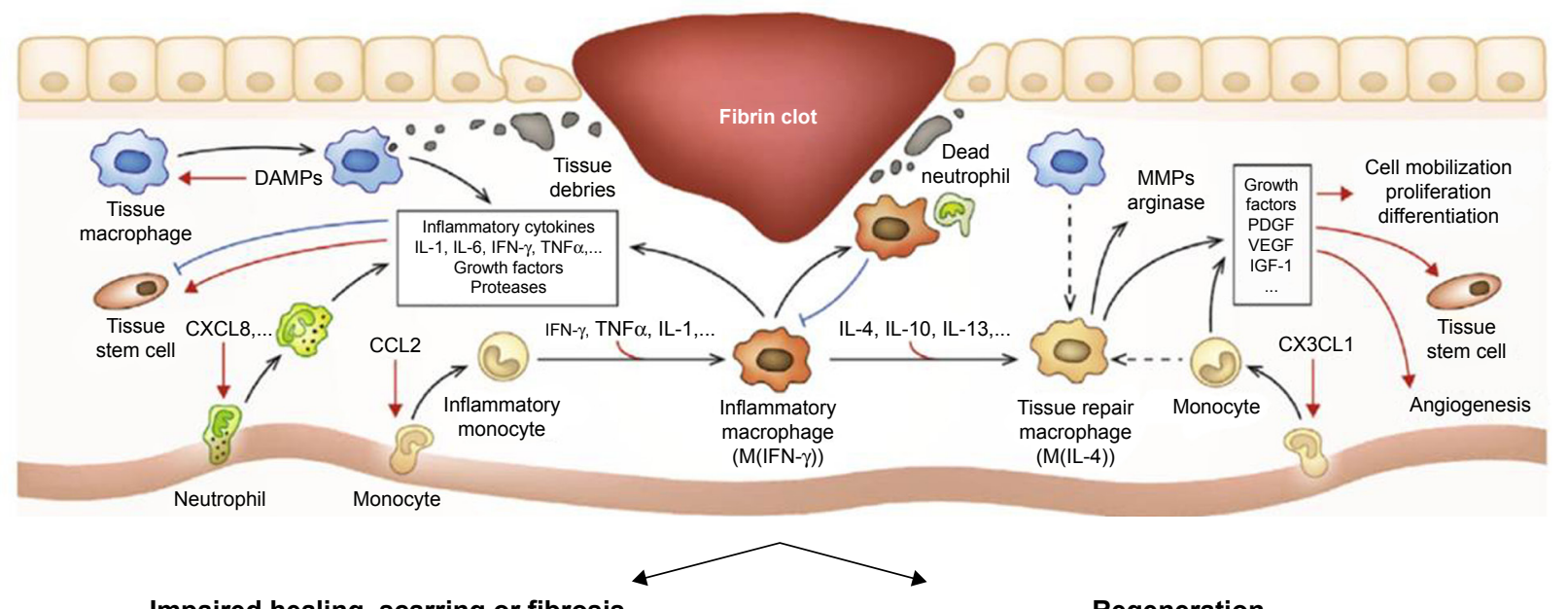

Impaired healing, scarring or fibrosis
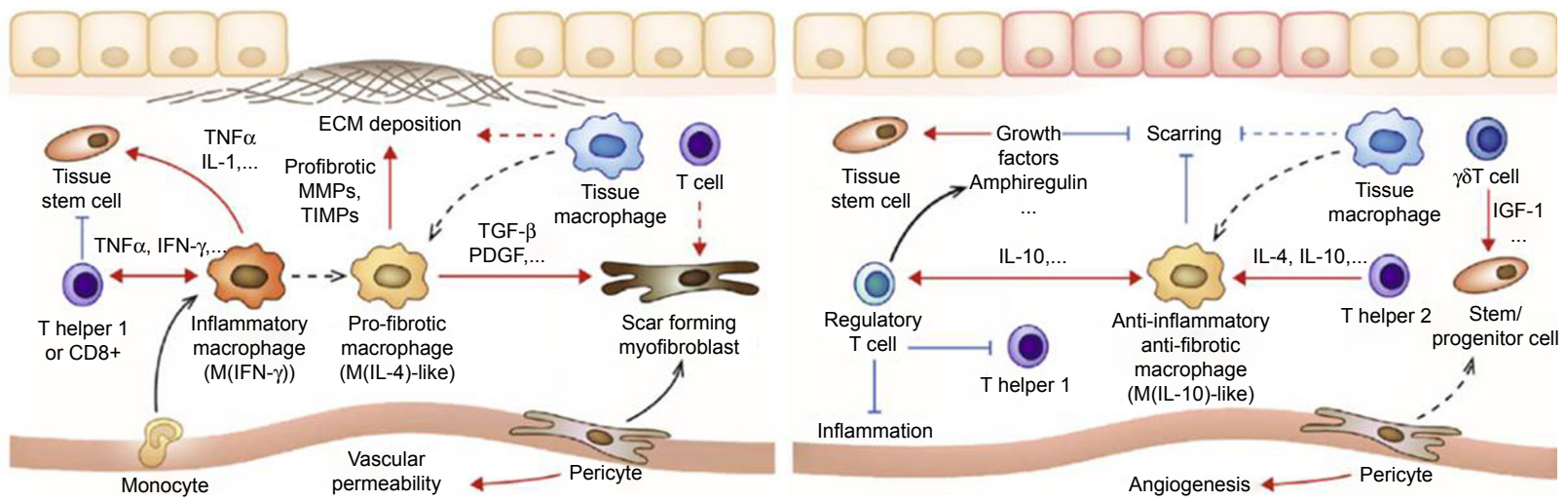

Figure 7 Multiple immunologic reactions during tissue repair and regeneration process.

Notes: Biomaterials-based tissue-engineered scaffolds are developed to deliver molecules, which promote regenerative pathways rather than proinflammatory pathways. Reprinted from Acta Biomater, 53, Julier Z, Park AJ, Briquez PS, Martino MM, Promoting tissue regeneration by modulating the immune system, 13-28, Copyright (2017), with permission from Elsevier. ${ }^{197}$

Abbreviations: ECM, extracellular matrix; IFN, interferon; IGF, insulin-like growth factor; MMP, matrix metalloproteinase; PDGF, platelet-derived growth factor; TIMP, tissue inhibitor of metalloproteinase; TNF, tumor necrosis factor; VEGF, vascular endothelial growth factor.

and cytokines such as IGF-1, KGF-1 (fibroblast growth factor 7 [FGF-7]), KGF-2 (FGF-10), IL-22, and IL-17A, thus controlling the repair or regeneration process. Overall, it can be understood that there is a need to balance the inflammatory reaction and tissue regeneration and currently there are lots of research carried out to develop biomaterials that can modulate these immunologic reactions and help in the cardiac tissue regeneration process. ${ }^{197,198}$

Projahn et al developed two hydrogels with different biodegradation properties, which could release two chemokines at different rates. They synthesized fast degradable hydrogel, which was tuned to release Met-CCL5 (a chemokine that inhibits neutrophil infiltration) within 24 hours of implantation, while slow degradable hydrogel releases recombinant protease-resistant CXCL12 (S4V) (a chemokine that stimulates hematopoietic stem cell recruitment thereby improving neovascularization) for 4 weeks in a controlled manner. They found that due to the temporal control of these chemokines' release, there is a significant suppression of initial neutrophils, reduction of apoptosis, and promotion of neovascularization, which leads to an improvement in the cardiac function after MI. ${ }^{199}$ In another study, Kim et al treated mesenchymal stem cells with TNF $\alpha$ before transplantation into MI heart in a rat model. They found that treatment of these stem cells with TNF $\alpha$ improved their engraftment with the tissue and enhanced the recovery of cardiac tissue after MI. They found that this might be because of the expression of BMP2 as a result of this treatment. ${ }^{200}$ Chen et al devised a heparin-based coacervate delivery system for the controlled delivery of an angiogenic factor FGF2 and an anti-inflammatory cytokine, IL-10. When this coacervate system was injected into mouse MI model, they found an improvement in the long-term LV contractile function, LV myocardial elasticity, and revascularization. They also 
observed mitigation of LV dilation, LV fibrosis, and also chronic inflammation at the infarct site. ${ }^{201}$ Thus, these are few strategies by which immunomodulation can augment the regenerative strategies that we had discussed earlier in this review.

\section{Future directions}

Despite so much advancement in 3D printing technology and its applications in cardiac tissue engineering, diagnostics, education, and treatments of CVDs, there is still space for future improvements. Areas such as advancements in image acquisition with high resolution, segmentation software, printing speed and resolution, cost, and printer types need further advancements. Future progress in printing materials and use of hybrid materials will reduce the gap between mechanical properties of scaffold and their respective demand for cardiovascular tissues. The applications of 3D printer will continue to grow in the field of bioprinting, a scaffold-free approach to get fully functional cardiac construct and blood vessels. Demand of whole organ and engineered vessels will keep growing by time with high aging population and rise in chronic illness. ${ }^{202}$ In future, this $3 \mathrm{D}$ bioprinting technology will move toward personalized tissue engineering, as it can be potentially utilized in fabricating customized devices, cardiac patches, arteries and vessels, valve, and prosthesis. Already few hospitals have demonstrated patients special models of various cardiovascular pathologies by using combined technologies of hybrid material 3D printing, high-spatial resolution cardiac imaging, and image processing software. ${ }^{168,203,204}$ Further, each university and hospital will invest in this field to print their own models and will use them as essential standard teaching modules along with conventional radiologic imaging. This notion of a personalized 3D printed cardiovascular solution is not here today, but is now clearly expected on the horizon. As diagnostic modalities, quality assurance programs will start as 3D printing is expected to be subject to more federal regulations. 3D printing will be a major advancement in setting new trends in diagnostics and therapeutics. For one, it would be expected that efforts toward direct in vivo bioprinting of biomimetic constructs to replace and enhance regeneration of compromised organ parts would eventually be realized in clinics. With enhancement of precision and optimum 3D printed product, shifting of this technology to robotic instruments for simplifying and scalable automated biofabrication along with portable bioprinters will be the focus areas of future research. To meet with the future increased demand of organs and vascular structures, fast and smart bioprinters will be required in clinics to construct reliably clinically relevant constructs according to the demand of patients as compared to today's slow bioprinters used in laboratory for research. Similarly, brick and building concept will be also a future model of bioprinting, in which minitissue blocks will be fabricated and scale up by joining them to get whole organ or part of organ according to the patient demand or the other approach may employ bioprinting of macroscale vascular network in tandem with microvascularized tissue strands. Importantly, stem cell technologies will play an essential role in transferring these thoughts into reality. For example, cytograft's lfeline vascular graft requires 6-9 months of developing time before it is ready for implantation. Most of this time is passed in culturing fibroblast sheets. The iPSC-derived SMCs have been shown to generate abundant collagen within 8-9 weeks of culture time. ${ }^{205}$ This high proliferation ability of iPSCs will not reduce the bioink production time but eliminate the need for harvesting cells from patients or donors. ${ }^{206}$

\section{Conclusion}

CVDs are among the leading cause of morbidity and mortality globally. Due to lack of organ donors, alternative approaches to repair $\mathrm{MI}$ and restore cardiac functions are essential. Tissue engineering and especially 3D scaffold and $3 \mathrm{D}$ printing showed significant success to develop artificial heart constructs. But still fabricating properly functional tissue construct for clinical applications depends on the availability of biomimetic materials with fine ECM feature and electrical conductance properties. To some extent supply of oxygen to artificial tissue construct is addressed by oxygen generation biomaterials. These biomaterials along with conductive elastomers are future of cardiac tissue engineering to address ischemia and spontaneous contractions issues with newly constructed cardiac tissue. Furthermore, $3 \mathrm{D}$ printed advanced bioreactors that can integrate electrical and mechanical stimulation will be another potential area for developing functional heart. 3D microfabrication technique is designed to engineer a highly vascularized cardiac construct on chip with controlled nutrient supply. Seeding of the 3D micropatterned chips with stem cell, growth factors, and other small biomolecules will give well cardiogenic differentiated and prevascularized functional heart constructs. 3D bioprinting using tissue spheroids is an attractive alternative as it allows customized tissue design without the use of scaffolds and avoids the problems with 
cell injury during the dispensing of the biomaterial. Decellularization of heart tissue can be a solution as it can create constructs with native alignments of cells. In future there is a need to integrate all conventional 3D tissue engineering techniques with modern scaffold-free 3D bioprinting to achieve the most realistic functional heart to address the burden of CVDs.

\section{Acknowledgments}

Although we are the authors of this review, we would never have been able to complete it without the great contribution of many people in the field of cardiac and vascular tissue engineering. We owe our gratitude to all those researchers who have made this review possible. We have cited as many references as permitted and apologize to the authors of those publications that we have not cited due to limitation of references. We apologize to other authors who have worked on these aspects but whom we have unintentionally overlooked. This work was supported by a grant from the Science Research Center (2015R1A5A1009701) of the National Research Foundation of Korea.

\section{Disclosure}

The authors report no conflicts of interest in this work.

\section{References}

1. Roth GA, Johnson C, Abajobir A, et al. Global, regional, and national burden of cardiovascular diseases for 10 causes, 1990 to 2015. J Am Coll Cardiol. 2017;70(1):1-25.

2. Writing Group Members, Mozaffarian D, Benjamin EJ, et al. Heart disease and stroke Statistics-2016 update: a report from the American Heart Association. Circulation. 2016;133(4):e38-e360.

3. Townsend N, Nichols M, Scarborough P, Rayner M. Cardiovascular disease in Europe - epidemiological update 2015. Eur Heart J. 2015; 36(40):2696-2705.

4. Carabello BA, Crawford FA. Valvular heart disease. $N$ Engl J Med. 1997;337(1):32-41.

5. Mickell JJ, Mathews RA, Park SC, et al. Left atrioventricular valve atresia: clinical management. Circulation. 1980;61(1):123-127.

6. Leoni D, Rello J. Cardiac arrest among patients with infections: causes, clinical practice and research implications. Clin Microbiol Infect. 2017;23(10):730-735.

7. Wilcken DEL. Clinical physiology of the normal heart. Oxford Textb Med. 2010;30:2619-2627.

8. Shadrin IY, Allen BW, Qian Y, et al. Cardiopatch platform enables maturation and scale-up of human pluripotent stem cell-derived engineered heart tissues. Nat Commun. 2017;8(1):1825.

9. Al-Aqeedi R, Asaad N, Al-Qahtani A, et al. Acute coronary syndrome in patients with prior coronary artery bypass surgery: observations from a 20-year registry in a Middle-Eastern country. PLoS One. 2012; 7(7):e40571.

10. Tchantchaleishvili V, Schubmehl H, Swartz MF, Hallinan W, Massey HT. Evolving strategies in the treatment of acute myocardial infarction-induced cardiogenic shock. Ann Cardiothorac Surg. 2014; 3(6):606-611.
11. Acharya D, Loyaga-Rendon RY, Pamboukian SV, et al. Ventricular assist device in acute myocardial infarction. J Am Coll Cardiol. 2016; 67(16):1871-1880.

12. Alrefai MT, Murali D, Paul A, et al. Cardiac tissue engineering and regeneration using cell-based therapy. Stem Cells Cloning. 2015;8: 81-101.

13. White SL, Hirth R, Mahíllo B, et al. The global diffusion of organ transplantation: trends, drivers and policy implications. Bull World Health Organ. 2014;92(11):826-835.

14. Sürder D, Schwitter J, Moccetti T, et al. Cell-based therapy for myocardial repair in patients with acute myocardial infarction: rationale and study design of the Swiss multicenter intracoronary stem cells study in acute myocardial infarction (SWISS-AMI). Am Heart J. 2010;160(1):58-64.

15. Zimmermann W, Didie M, Doker S, et al. Heart muscle engineering: an update on cardiac muscle replacement therapy. Cardiovasc Res. 2006; 71(3):419-429.

16. O’Neill HS, Gallagher LB, O’Sullivan J, et al. Biomaterial-enhanced cell and drug delivery: lessons learned in the cardiac field and future perspectives. Adv Mater. 2016;28(27):5648-5661.

17. Domenech M, Polo-Corrales L, Ramirez-Vick JE, Freytes DO. Tissue engineering strategies for myocardial regeneration: acellular versus cellular scaffolds? Tissue Eng B Rev. 2016;22(6):438-458.

18. Wang QL, Wang HJ, Li ZH, et al. Mesenchymal stem cell-loaded cardiac patch promotes epicardial activation and repair of the infarcted myocardium. J Cell Mol Med. 2017;21(9):1751-1766.

19. Wollert KC, Meyer GP, Lotz J, et al. Intracoronary autologous bonemarrow cell transfer after myocardial infarction: the boost randomised controlled clinical trial. Lancet. 2004;364(9429):141-148.

20. Assmus B, Schächinger V, Teupe C, et al. Transplantation of progenitor cells and regeneration enhancement in acute myocardial infarction (TOPCARE-AMI). Circulation. 2002;106(24):3009-3017.

21. Wollert KC, Meyer GP, Lotz J, et al. Intracoronary autologous bonemarrow cell transfer after myocardial infarction: the boost randomised controlled clinical trial. Lancet. 2004;364(9429):141-148.

22. Schächinger V, Erbs S, Elsässer A, et al. Improved clinical outcome after intracoronary administration of bone-marrow-derived progenitor cells in acute myocardial infarction: final 1-year results of the REPAIRAMI trial. Eur Heart J. 2006;27(23):2775-2783.

23. Thavandiran N, Nunes SS, Xiao Y, Radisic M. Topological and electrical control of cardiac differentiation and assembly. Stem Cell Res Ther. 2013;4(1):14.

24. Vunjak-Novakovic G, Tandon N, Godier A, et al. Challenges in cardiac tissue engineering. Tissue Eng Part B Rev. 2010;16(2):169-187.

25. Visone R, Gilardi M, Marsano A, et al. Cardiac meets skeletal: what's new in microfluidic models for muscle tissue engineering. Molecules. 2016;21(9) pii: E1128.

26. Duan B, Kapetanovic E, Hockaday LA, Butcher JT. Three-dimensional printed trileaflet valve conduits using biological hydrogels and human valve interstitial cells. Acta Biomater. 2014;10(5):1836-1846.

27. Guyette JP, Charest JM, Mills RW, et al. Bioengineering human myocardium on native extracellular matrix. Circ Res. 2016;118(1):56-72.

28. Liu Q, Tian S, Zhao C, et al. Porous nanofibrous poly(L-lactic acid) scaffolds supporting cardiovascular progenitor cells for cardiac tissue engineering. Acta Biomater. 2015;26:105-114.

29. Nistor M-T, Chiriac AP, Nita LE, Vasile C, Verestiuc L. Upon the characterization of semi-synthetic hydrogels based on poly (NIPAM) inserted onto collagen sponge. Compos B Eng. 2012;43(3):1508-1515.

30. Qasim M, Lim DJ, Park H, Na D. Nanotechnology for diagnosis and treatment of infectious diseases. J Nanosci Nanotechnol. 2014;14(10): 7374-7387.

31. Chen Y, Zeng D, Ding L, et al. Three-dimensional poly-( $\varepsilon$-caprolactone) nanofibrous scaffolds directly promote the cardiomyocyte differentiation of murine-induced pluripotent stem cells through Wnt/ $\beta$-catenin signaling. BMC Cell Biol. 2015;16:22.

32. Liu BH, Yeh HY, Lin YC, et al. Spheroid formation and enhanced cardiomyogenic potential of adipose-derived stem cells grown on chitosan. Biores Open Access. 2013;2(1):28-39. 
33. Prabhakaran MP, Kai D, Ghasemi-Mobarakeh L, Ramakrishna S. Electrospun biocomposite nanofibrous patch for cardiac tissue engineering. Biomed Mater. 2011;6(5):055001.

34. Ravichandran R, Sridhar R, Venugopal JR, et al. Gold nanoparticle loaded hybrid nanofibers for cardiogenic differentiation of stem cells for infarcted myocardium regeneration. Macromol Biosci. 2014;14(4): 515-525

35. Galperin A, Long TJ, Ratner BD. Degradable, thermo-sensitive poly $(N$ isopropyl acrylamide)-based scaffolds with controlled porosity for tissue engineering applications. Biomacromolecules. 2010;11(10):2583-2592.

36. Xu Y, Patnaik S, Guo X, et al. Cardiac differentiation of cardiospherederived cells in scaffolds mimicking morphology of the cardiac extracellular matrix. Acta Biomater. 2014;10(8):3449-3462.

37. Laschke MW, Menger MD. Life is $3 \mathrm{~d}$ : boosting spheroid function for tissue engineering. Trends Biotechnol. 2017;35(2):133-144.

38. Ou KL, Hosseinkhani H. Development of 3D in vitro technology for medical applications. Int J Mol Sci. 2014;15(10):17938-17962.

39. Amann A, Zwierzina M, Koeck S, et al. Development of a 3D angiogenesis model to study tumour - endothelial cell interactions and the effects of anti-angiogenic drugs. Sci Rep. 2017;7(1):2963.

40. van Duinen V, Trietsch SJ, Joore J, Vulto P, Hankemeier T. Microfluidic 3D cell culture: from tools to tissue models. Curr Opin Biotechnol. 2015;35:118-126.

41. Han J, Wu Q, Xia Y, Wagner MB, Xu C. Cell alignment induced by anisotropic electrospun fibrous scaffolds alone has limited effect on cardiomyocyte maturation. Stem Cell Res. 2016;16(3):740-750.

42. Chong JJ, Yang X, don CW, et al. Human embryonic-stem-cellderived cardiomyocytes regenerate non-human primate hearts. Nature. 2014;510(7504):273-277.

43. Valverde I. Three-dimensional printed cardiac models: applications in the field of medical education, cardiovascular surgery, and structural heart interventions. Rev Esp Cardiol. 2017;70(4):282-291.

44. Wang Z, Lee SJ, Cheng HJ, Yoo JJ, Atala A. 3D bioprinted functional and contractile cardiac tissue constructs. Acta Biomater. 2018;70:48-56.

45. Kensah G, Roa Lara A, Dahlmann J, et al. Murine and human pluripotent stem cell-derived cardiac bodies form contractile myocardial tissue in vitro. Eur Heart J. 2013;34(15):1134-1146.

46. Caspi O, Lesman A, Basevitch Y, et al. Tissue engineering of vascularized cardiac muscle from human embryonic stem cells. Circ Res. 2007; 100(2):263-272.

47. Conant G, Lai BFL, Lu RXZ, et al. High-content assessment of cardiac function using heart-on-a-chip devices as drug screening model. Stem Cell Rev Rep. 2017;13(3):335-346.

48. Mladěnka P, Applová L, Patočka J, et al. Comprehensive review of cardiovascular toxicity of drugs and related agents. Med Res Rev. 2018; 38(4):1332-1403.

49. Saludas L, Pascual-Gil S, Prósper F, Garbayo E, Blanco-Prieto M. Hydrogel based approaches for cardiac tissue engineering. Int J Pharm. 2017;523(2):454-475.

50. Xu B, Li Y, Deng B, et al. Chitosan hydrogel improves mesenchymal stem cell transplant survival and cardiac function following myocardial infarction in rats. Exp Ther Med. 2017;13(2):588-594.

51. Kim PH, Cho JY. Myocardial tissue engineering using electrospun nanofiber composites. BMB Rep. 2016;49(1):26-36.

52. Yuan X, He B, Lv Z, Luo S. Fabrication of self-assembling peptide nanofiber hydrogels for myocardial repair. RSC Adv. 2014;4(96): 53801-53811.

53. Joshi J, Kothapalli CR. Nanofibers based tissue engineering and drug delivery approaches for myocardial regeneration. Curr Pharm Des. 2015;21(15):2006-2020.

54. Balashov V, Efimov A, Agapova O, et al. High resolution 3D microscopy study of cardiomyocytes on polymer scaffold nanofibers reveals formation of unusual sheathed structure. Acta Biomater. 2018;68: 214-222.

55. Martins AM, Eng G, Caridade SG, et al. Electrically conductive chitosan/ carbon scaffolds for cardiac tissue engineering. Biomacromolecules. 2014;15(2):635-643.
56. Gilpin A, Yang Y. Decellularization strategies for regenerative medicine: from processing techniques to applications. Biomed Res Int. 2017;2017:1-13

57. Lu TY, Lin B, Kim J. Repopulation of decellularized mouse heart with human induced pluripotent stem cell-derived cardiovascular progenitor cells. Nat Commun. 2013;4:1-11.

58. Taylor DA, Parikh RB, Sampaio LC. Bioengineering hearts: simple yet complex. Curr Stem Cell Rep. 2017;3(1):35-44.

59. Vunjak-Novakovic G, Lui KO, Tandon N, Chien KR. Bioengineering heart muscle: a paradigm for regenerative medicine. Annu Rev Biomed Eng. 2011;13:245-267.

60. Sidorov VY, Samson PC, Sidorova TN, et al. I-Wire Heart-on-a-Chip I: three-dimensional cardiac tissue constructs for physiology and pharmacology. Acta Biomater. 2017;48:68-78.

61. Zhu W, Qu X, Zhu J, et al. Direct 3D bioprinting of prevascularized tissue constructs with complex microarchitecture. Biomaterials. 2017; 124:106-115.

62. Chiono V, Mozetic P, Boffito M, et al. Polyurethane-based scaffolds for myocardial tissue engineering. Interface Focus. 2014;4(1):20130045.

63. Jia W, Gungor-Ozkerim PS, Zhang YS, et al. Direct 3D bioprinting of perfusable vascular constructs using a blend bioink. Biomaterials. 2016;106:58-68

64. Zhang YS, Arneri A, Bersini S, et al. Bioprinting 3D microfibrous scaffolds for engineering endothelialized myocardium and heart-on-a-chip. Biomaterials. 2016;110:45-59.

65. Yoon S, Park JA, Lee HR, et al. Inkjet-spray hybrid printing for 3D freeform fabrication of multilayered hydrogel structures. Adv Healthc Mater. 2018;7:1-10.

66. Jammalamadaka U, Tappa K. Recent advances in biomaterials for 3D printing and tissue engineering. J Funct Biomater. 2018;9:22.

67. Mehesz AN, Brown J, Hajdu Z, et al. Scalable robotic biofabrication of tissue spheroids. Biofabrication. 2011;3(2):025002.

68. Mironov V, Visconti RP, Kasyanov V, et al. Organ printing: tissue spheroids as building blocks. Biomaterials. 2009;30(12):2164-2174.

69. Fatima A. Breast cancer copy number profiling of MammaPrint TM genes reveals association with the prognosis of breast cancer patients. 2017;20:246-253.

70. Mertz L. New world of 3-D printing offers "Completely New Ways of Thinking”: Q\&A with author, engineer, and 3-D printing expert Hod lipson. IEEE Pulse. 2013;4:12-14.

71. Ozbolat IT, Hospodiuk M. Current advances and future perspectives in extrusion-based bioprinting. Biomaterials. 2016;76:321-343.

72. Bakhshinejad A, D'Souza RM. A brief comparison between available bio-printing methods. In 2015 IEEE Great Lakes biomedical conference (GLBC) 1-3 (IEEE, 2015). 2015.

73. Ong CS, Fukunishi T, Zhang H, et al. Biomaterial-free three-dimensional bioprinting of cardiac tissue using human induced pluripotent stem cell derived cardiomyocytes. Sci Rep. 2017;7(1):4566.

74. Usprech J, Romero DA, Amon CH, Simmons CA. Combinatorial screening of 3D biomaterial properties that promote myofibrogenesis for mesenchymal stromal cell-based heart valve tissue engineering. Acta Biomater. 2017;58:34-43.

75. Bourget J, Guillemette M, Veres T, Auger FA, Germain L. Alignment of cells and extracellular matrix within tissue-engineered substitutes. Adv Biomater Sci Biomed Appl Ref. 2013:365-390.

76. Bell A, Kofron M, Nistor V. Multiphoton crosslinking for biocompatible 3D printing of type I collagen. Biofabrication. 2015;7(3):035007.

77. Gao L, Kupfer ME, Jung JP, et al. Myocardial tissue engineering with cells derived from human-induced pluripotent stem cells and a native-like, high-resolution, 3-dimensionally printed scaffold. Circ Res. 2017;120(8):1318-1325.

78. Cm H, Mishra A, Lin PT, et al. 3D printed polycaprolactone carbon nanotube composite scaffolds for cardiac tissue engineering. Macromol Biosci. 2017;17(4):1600250.

79. Mironov AV, Grigoryev AM, Krotova LI, et al. 3D printing of PLGA scaffolds for tissue engineering. J Biomed Mater Res A. 2017;105(1): 104-109. 
80. Mirabella AT, MacArthur JW, Cheng D. 3D printed vascular networks direct therapeutic angiogenesis in ischemia. Nat Biomed Eng. 2017;0083:1-6.

81. Tijore A, Irvine SA, Sarig U, et al. Contact guidance for cardiac tissue engineering using 3D bioprinted gelatin patterned hydrogel. Biofabrication. 2017;10(2):025003.

82. Fleischer S, Shapira A, Feiner R, Dvir T. Modular assembly of thick multifunctional cardiac patches. Proc Natl Acad Sci U S A. 2017; 114(8):1898-1903.

83. Maiullari F, Costantini M, Milan M, et al. A multi-cellular 3D bioprinting approach for vascularized heart tissue engineering based on HUVECs and iPSC-derived cardiomyocytes. Sci Rep. 2018; 8(1):1-15.

84. Siltanen A, Kitabayashi K, Lakkisto P, et al. hHGF overexpression in myoblast sheets enhances their angiogenic potential in rat chronic heart failure. PLoS One. 2011;6(4):e19161.

85. Takahashi H, Okano T. Cell sheet-based tissue engineering for organizing anisotropic tissue constructs produced using microfabricated thermoresponsive substrates. Adv Healthc Mater. 2015;4(16): 2388-2407.

86. Wang H, Shi J, Wang Y, et al. Promotion of cardiac differentiation of brown adipose derived stem cells by chitosan hydrogel for repair after myocardial infarction. Biomaterials. 2014;35(13):3986-3998.

87. Hamid T, Prabhu SD. Immunomodulation is the key to cardiac repair. Circ Res. 2017;120(10):1530-1532.

88. Majka M, Sułkowski M, Badyra B, Musiałek P. Concise review: mesenchymal stem cells in cardiovascular regeneration: emerging research directions and clinical applications. Stem Cells Transl Med. 2017;6(10):1859-1867.

89. Caplan AI. Cell Sources for Tissue Engineering: Mesenchymal Stem Cells. Biomaterials Science: An Introduction to Materials. 3rd ed. MA, USA: Elsevier; 2013.

90. Michler RE. Stem cell therapy for heart failure. Methodist Debakey Cardiovasc J. 2013;9(4):187-194.

91. Thomson JA, Itskovitz-Eldor J, Shapiro SS, et al. Embryonic stem cell lines derived from human blastocysts. Science. 1998;282(5391): 1145-1147.

92. Takahashi K, Yamanaka S. Induction of pluripotent stem cells from mouse embryonic and adult fibroblast cultures by defined factors. Cell. 2006;126(4):663-676.

93. Kehat I, Khimovich L, Caspi O, et al. Electromechanical integration of cardiomyocytes derived from human embryonic stem cells. Nat Biotechnol. 2004;22(10):1282-1289.

94. Lian X, Hsiao C, Wilson G, et al. Robust cardiomyocyte differentiation from human pluripotent stem cells via temporal modulation of canonical Wnt signaling. Proc Natl Acad Sci U S A. 2012;109(27): E1848-E1857.

95. Mummery CL, Zhang J, Ng ES, et al. Differentiation of human embryonic stem cells and induced pluripotent stem cells to cardiomyocytes: a methods overview. Circ Res. 2012;111(3):344-358.

96. Csobonyeiova M, Polak S, Koller J, Danisovic L. Induced pluripotent stem cells and their implication for regenerative medicine. Cell Tissue Bank. 2015;16(2):171-180.

97. Amabile G, Meissner A. Induced pluripotent stem cells: current progress and potential for regenerative medicine. Trends Mol Med. 2009;15(2):59-68.

98. Bedada FB, Wheelwright M, Metzger JM. Maturation status of sarcomere structure and function in human iPSC-derived cardiac myocytes. Biochim Biophys Acta Mol Cell Res. 2016;1863(7):1829-1838.

99. Galdos FX, Guo Y, Paige SL, et al. Cardiac regeneration: lessons from development. Circ Res. 2017;120(6):941-959.

100. Chong J, Yang X, don C, et al. PW281 human pluripotent stem cell derived cardiomyocytes regenerate infarcted hearts of non-human primates. Glob Heart. 2014;9(1):e315-e316.

101. Cambria E, Pasqualini FS, Wolint P, et al. Translational cardiac stem cell therapy: advancing from first-generation to next-generation cell types. NPJ Regen Med. 2017;2(1):17.
102. Gaetani R, Feyen DA, Verhage V, et al. Epicardial application of cardiac progenitor cells in a 3D-printed gelatin/hyaluronic acid patch preserves cardiac function after myocardial infarction. Biomaterials. 2015;61:339-348.

103. Gao L, Kupfer ME, Jung JP, et al. Myocardial tissue engineering with cells derived from human-induced pluripotent stem cells and a native-like, high-resolution, 3-dimensionally printed scaffold. Circ Res. 2017;120(8):1318-1325.

104. Ong CS, Fukunishi T, Zhang H, et al. Biomaterial-Free threedimensional bioprinting of cardiac tissue using human induced pluripotent stem cell derived cardiomyocytes. Sci Rep. 2017;7(1):2-12.

105. Zhang B, Montgomery M, Chamberlain MD, et al. Biodegradable scaffold with built-in vasculature for cardiac tissue vascularization and surgical vascular anastomosis. Nat Mater. 2016;15(6):669-678.

106. Feinberg AW, Feigel A, Shevkoplyas SS, et al. Muscular thin films for building actuators and powering devices. Science. 2007; 317(5843):1366-1370.

107. Tanaka Y, Morishima K, Shimizu T, et al. Demonstration of a PDMSbased bio-microactuator using cultured cardiomyocytes to drive polymer micropillars. Lab Chip. 2006;6(2):230.

108. Sheehy SP, Grosberg A, Qin P, et al. Toward improved myocardial maturity in an organ-on-chip platform with immature cardiac myocytes. Exp Biol Med. 2017;242(17):1643-1656.

109. Elhassa GO. Drug development: stages of drug development. J Pharmacovigil. 2015;03(03):140-142.

110. Varga ZV, Ferdinandy P, Liaudet L, Pacher P. Drug-induced mitochondrial dysfunction and cardiotoxicity. Am J Physiol Hear Circ Physiol. 2015;309(9):H1453-H1467.

111. Marsano A, Conficconi C, Lemme M, et al. Beating heart on a chip: a novel microfluidic platform to generate functional 3D cardiac microtissues. Lab Chip. 2016;16:599-610.

112. Zhang B, Montgomery M, Chamberlain MD, et al. Biodegradable scaffold with built-in vasculature for organ-on-a-chip engineering and direct surgical anastomosis. Nat Mater. 2016;15(6):669-678.

113. Horton RE, Yadid M, Mccain ML, et al. Angiotensin II induced cardiac dysfunction on a chip. PLoS One. 2016;11(1):e0146415.

114. Kobuszewska A, Tomecka E, Zukowski K, et al. Heart-on-a-Chip: an investigation of the influence of static and perfusion conditions on cardiac (H9c2) cell proliferation, morphology, and alignment. SLAS Technol. 2017;22(5):536-546.

115. Skardal A, Murphy SV, Devarasetty M, et al. Multi-tissue interactions in an integrated three-tissue organ-on-a-chip platform. Sci Rep. 2017;7(1):1-16

116. Lind JU, Busbee TA, Valentine AD, et al. Instrumented cardiac microphysiological devices via multimaterial three-dimensional printing. Nat Mater. 2017;16(3):303-308.

117. Hasan A, Saliba J, Pezeshgi Modarres H, et al. Micro and nanotechnologies in heart valve tissue engineering. Biomaterials. 2016;103: 278-292.

118. Maidhof R, Tandon N, Lee EJ, et al. Biomimetic perfusion and electrical stimulation applied in concert improved the assembly of engineered cardiac tissue. J Tissue Eng Regen Med. 2012;6(10):e12-e23.

119. Tandon N, Taubman A, Cimetta E, Saccenti L, Vunjak-Novakovic G. Portable bioreactor for perfusion and electrical stimulation of engineered cardiac tissue. Conf Proc IEEE Eng Med Biol Soc. 2013;2013: 6219-6223.

120. Brown MA, Iyer RK, Radisic M. Pulsatile perfusion bioreactor for cardiac tissue engineering. Biotechnol Prog. 2008;24(4):907-920.

121. Owaki T, Shimizu T, Yamato M, Okano T. Cell sheet engineering for regenerative medicine: current challenges and strategies. Biotechnol J. 2014;9(7):904-914.

122. Lee K, Kim C, Young Yang J, et al. Gravity-oriented microfluidic device for uniform and massive cell spheroid formation. Biomicrofluidics. 2012;6(1):014114.

123. Tung YC, Hsiao AY, Allen SG, et al. High-throughput 3D spheroid culture and drug testing using a 384 hanging drop array. Analyst. 2011; 136(3):473-478. 
124. Fu CY, Tseng SY, Yang SM, et al. A microfluidic chip with a U-shaped microstructure array for multicellular spheroid formation, culturing and analysis. Biofabrication. 2014;6(1):015009.

125. Li Q, Chow AB, Mattingly RR. Three-dimensional overlay culture models of human breast cancer reveal a critical sensitivity to mitogenactivated protein kinase kinase inhibitors. J Pharmacol Exp Ther. 2010; 332(3):821-828.

126. Barrila J, Radtke AL, Crabbé A, et al. Organotypic 3D cell culture models: using the rotating wall vessel to study host-pathogen interactions. Nat Rev Microbiol. 2010;8(11):791-801.

127. Tan Y, Richards DJ, Trusk TC, et al. 3D printing facilitated scaffoldfree tissue unit fabrication. Biofabrication. 2014;6(2):024111.

128. Noguchi R, Nakayama K, Itoh M, et al. Development of a threedimensional pre-vascularized scaffold-free contractile cardiac patch for treating heart disease. J Heart Lung Transplant. 2016;35(1):137-145.

129. Song HG, Rumma RT, Ozaki CK, Edelman ER, Chen CS. Vascular tissue engineering: progress, challenges, and clinical promise. Cell Stem Cell. 2018;22(3):340-354.

130. Datta P, Ayan B, Ozbolat IT. Bioprinting for vascular and vascularized tissue biofabrication. Acta Biomater. 2017;51:1-20.

131. Murphy SV, Atala A. 3D bioprinting of tissues and organs. Nat Biotechnol. 2014;32(8):773-785.

132. Murphy SV, Skardal A, Atala A. Evaluation of hydrogels for bioprinting applications. J Biomed Mater Res A. 2013;101A(1):272-284.

133. Gao Q, Liu Z, Lin Z, et al. 3D bioprinting of vessel-like structures with multilevel fluidic channels. ACS Biomater Sci Eng. 2017;3(3): 399-408.

134. Hinton TJ, Jallerat Q, Palchesko RN, et al. Three-dimensional printing of complex biological structures by freeform reversible embedding of suspended hydrogels. Sci Adv. 2015;1(9):e1500758.

135. Malda J, Visser J, Melchels FP, et al. 25th anniversary article: engineering hydrogels for biofabrication. Adv Mater. 2013;25(36):5011-5028.

136. Hoch E, Tovar GEM, Borchers K. Bioprinting of artificial blood vessels: current approaches towards a demanding goal. Eur J CardioThoracic Surg. 2014;46(5):767-778.

137. Kang HW, Lee SJ, Ko IK, et al. A 3D bioprinting system to produce human-scale tissue constructs with structural integrity. Nat Biotechnol. 2016;34(3):312-319.

138. Kolesky DB, Homan KA, Skylar-Scott MA, Lewis JA. Threedimensional bioprinting of thick vascularized tissues. Proc Natl Acad Sci US A. 2016;113(12):3179-3184.

139. van der Meer AD, Orlova VV, Ten Dijke P, van den Berg A, Mummery CL. Three-dimensional co-cultures of human endothelial cells and embryonic stem cell-derived pericytes inside a microfluidic device. Lab Chip. 2013;13(18):3562.

140. Chrobak KM, Potter DR, Tien J. Formation of perfused, functional microvascular tubes in vitro. Microvasc Res. 2006;71(3):185-196.

141. Hasan A, Paul A, Vrana NE, et al. Microfluidic techniques for development of 3D vascularized tissue. Biomaterials. 2014;35(26):7308-7325.

142. Norotte C, Marga FS, Niklason LE, Forgacs G. Scaffold-free vascular tissue engineering using bioprinting. Biomaterials. 2009;30(30): 5910-5917.

143. Kucukgul C, Ozler SB, Inci I, et al. 3D bioprinting of biomimetic aortic vascular constructs with self-supporting cells. Biotechnol Bioeng. 2015;112(4):811-821.

144. Cui X, Boland T. Human microvasculature fabrication using thermal inkjet printing technology. Biomaterials. 2009;30(31):6221-6227.

145. Fukunishi T, Best CA, Sugiura T, et al. Preclinical study of patientspecific cell-free nanofiber tissue-engineered vascular grafts using 3-dimensional printing in a sheep model. J Thorac Cardiovasc Surg. 2017;153(4):924-932.

146. Schöneberg J, de Lorenzi F, Theek B, et al. Engineering biofunctional in vitro vessel models using a multilayer bioprinting technique. $\mathrm{Sci}$ Rep. 2018;8(1):10430.

147. Pinnock CB, Meier EM, Joshi NN, Wu B, Lam MT. Customizable engineered blood vessels using 3D printed inserts. Methods. 2016; 99(20-27):20-27.
148. Liu H, Zhou H, Lan H, et al. 3D printing of artificial blood vessel: study on multi-parameter optimization design for vascular molding effect in alginate and gelatin. Micromachines. 2017;8(8):237.

149. Jang J, Park HJ, Kim SW, et al. 3D printed complex tissue construct using stem cell-laden decellularized extracellular matrix bioinks for cardiac repair. Biomaterials. 2017;112:264-274.

150. Pati F, Cho DW. Bioprinting of 3D tissue models using decellularized extracellular matrix bioink. Methods Mol Biol. 2017;1612:381-390.

151. Itoh M, Nakayama K, Noguchi R, et al. Scaffold-free tubular tissues created by a Bio-3D printer undergo remodeling and endothelialization when implanted in rat aortae. PLoS One. 2015;10(9):e0136681.

152. Cabrera MS, Sanders B, Goor OJGM, et al. Computationally designed 3D printed self-expandable polymer stents with biodegradation capacity for minimally invasive heart valve implantation: a proof-ofconcept study. 3D Print Addit Manuf. 2017;4(1):19-29.

153. Fujita B, Kütting M, Seiffert M, et al. Calcium distribution patterns of the aortic valve as a risk factor for the need of permanent pacemaker implantation after transcatheter aortic valve implantation. Eur Heart J Cardiovasc Imaging. 2016;17(12):1385-1393.

154. Hernández-Enríquez M, Brugaletta S, Andreu D, et al. Threedimensional printing of an aortic model for transcatheter aortic valve implantation: possible clinical applications. Int J Cardiovasc Imaging. 2017;33(2):283-285.

155. Jung JI, Koh YS, Chang K. 3D printing model before and after transcatheter aortic valve implantation for a better understanding of the anatomy of aortic root. Korean Circ J. 2016;46(4):588-589.

156. Maragiannis D, Jackson MS, Igo SR, et al. Replicating patient-specific severe aortic valve stenosis with functional 3D modeling. Circ Cardiovasc Imaging. 2015;8(10):e003626.

157. Maragiannis D, Jackson MS, Igo SR, et al. Functional 3D printed patient-specific modeling of severe aortic stenosis. J Am Coll Cardiol. 2014;64(10):1066-1068.

158. Ho D, Squelch A, Sun Z. Modelling of aortic aneurysm and aortic dissection through 3D printing. J Med Radiat Sci. 2017;64(1):10-17.

159. Mafeld S, Nesbitt C, Mccaslin J, et al. Three-dimensional (3D) printed endovascular simulation models: a feasibility study. Ann Transl Med. 2017;5(3):42.

160. Fujita T, Saito N, Minakata K, et al. Transfemoral transcatheter aortic valve implantation in the presence of a mechanical mitral valve prosthesis using a dedicated TAVI guidewire: utility of a patient-specific three-dimensional heart model. Cardiovasc Interv Ther. 2017;32(3): 308-311.

161. Gallo M, D’Onofrio A, Tarantini G, et al. 3D-printing model for complex aortic transcatheter valve treatment. Int J Cardiol. 2016;210: 139-140.

162. Mashari A, Knio Z, Jeganathan J, et al. Hemodynamic testing of patient-specific mitral valves using a pulse duplicator: a clinical application of three-dimensional printing. J Cardiothorac Vasc Anesth. 2016;30(5):1278-1285.

163. Vukicevic M, Puperi DS, Jane Grande-Allen K, Little SH. 3D printed modeling of the mitral valve for catheter-based structural interventions. Ann Biomed Eng. 2017;45(2):508-519.

164. Witschey WR, Pouch AM, Mcgarvey JR, et al. Three-dimensional ultrasound-derived physical mitral valve modeling. Ann Thorac Surg. 2014;98(2):691-694.

165. Bartel T, Rivard A, Jimenez A, Mestres CA, Müller S. Medical threedimensional printing opens up new opportunities in cardiology and cardiac surgery. Eur Heart J. 2018;39(15):1246-1254.

166. Jacobs S, Grunert R, Mohr FW, Falk V. 3D-imaging of cardiac structures using $3 \mathrm{D}$ heart models for planning in heart surgery: a preliminary study. Interact Cardiovasc Thorac Surg. 2008;7(1):6-9.

167. Martelli N, Serrano C, van den Brink H, et al. Advantages and disadvantages of 3-dimensional printing in surgery: a systematic review. Surgery. 2016;159(6):1485-1500.

168. Schmauss D, Haeberle S, Hagl C, Sodian R. Three-dimensional printing in cardiac surgery and interventional cardiology: a single-centre experience. Eur J Cardio-Thoracic Surg. 2015;47(6):1044-1052. 
169. Yang DH, Kang JW, Kim N, et al. Myocardial 3-dimensional printing for septal myectomy guidance in a patient with obstructive hypertrophic cardiomyopathy. Circulation. 2015;132(4):300-301.

170. Valverde I, Gomez G, Gonzalez A, et al. Three-dimensional patientspecific cardiac model for surgical planning in Nikaidoh procedure. Cardiol Young. 2015;25(4):698-704.

171. Huang J, Li G, Wang W, Wu K, Le T. 3D printing guiding stent graft fenestration: a novel technique for fenestration in endovascular aneurysm repair. Vascular. 2017;25(4):442-446.

172. Schmauss D, Gerber N, Sodian R. Three-dimensional printing of models for surgical planning in patients with primary cardiac tumors. J Thorac Cardiovasc Surg. 2013;145(5):1407-1408.

173. Tam MD, Latham TR, Lewis M, et al. A pilot study assessing the impact of 3-D printed models of aortic aneurysms on management decisions in EVAR planning. Vasc Endovascular Surg. 2016; 50(1):4-9.

174. Bhatla P, Tretter JT, Ludomirsky A, et al. Utility and scope of rapid prototyping in patients with complex muscular ventricular septal defects or double-outlet right ventricle: does it alter management decisions? Pediatr Cardiol. 2017;38(1):103-114.

175. Garekar S, Bharati A, Chokhandre M, et al. Clinical application and multidisciplinary assessment of three dimensional printing in double outlet right ventricle with remote ventricular septal defect. World $J$ Pediatr Congenit Heart Surg. 2016;7(3):344-350.

176. Biglino G, Capelli C, Koniordou D, et al. Use of 3D models of congenital heart disease as an education tool for cardiac nurses. Congenit Heart Dis. 2017;12(1):113-118.

177. Bramlet M, Olivieri L, Farooqi K, Ripley B, Coakley M. Impact of three-dimensional printing on the study and treatment of congenital heart disease. Circ Res. 2017;120(6):904-907.

178. Costello JP, Olivieri LJ, Krieger A, et al. Utilizing three-dimensional printing technology to assess the feasibility of high-fidelity synthetic ventricular septal defect models for simulation in medical education. World J Pediatr Congenit Heart Surg. 2014;5(3):421-426.

179. Farooqi KM, Uppu SC, Nguyen K, et al. Application of virtual threedimensional models for simultaneous visualization of intracardiac anatomic relationships in double outlet right ventricle. Pediatr Cardiol. 2016;37(1):90-98.

180. Valverde I. Three-dimensional printed cardiac models: applications in the field of medical education, cardiovascular surgery, and structural heart interventions. Rev Esp Cardiol. 2017;70(4):282-291.

181. Lim KH, Loo ZY, Goldie SJ, Adams JW, Mcmenamin PG. Use of 3D printed models in medical education: a randomized control trial comparing 3D prints versus cadaveric materials for learning external cardiac anatomy. Anat Sci Educ. 2016;9(3):213-221.

182. Abouhashem Y, Dayal M, Savanah S, Štrkalj G. The application of 3D printing in anatomy education. Med Educ Online. 2015;20:29847.

183. Drake RL, Pawlina W. An addition to the neighborhood: 3D printed anatomy teaching resources. Anat Sci Educ. 2014;7(6):419.

184. Estai M, Bunt S. Best teaching practices in anatomy education: a critical review. Ann Anat. 2016;208:151-157.

185. Coakley MF, Hurt DE, Weber N, et al. The NIH $3 D$ print exchange: a public resource for bioscientific and biomedical 3D prints. Addit Manuf. 2014;1(3):137-140.

186. Wood RP, Khobragade P, Ying L, et al. Initial testing of a 3D printed perfusion phantom using digital subtraction angiography. In Gimi B, Molthen RC, editors. Proceedings of SPIE - the International Society for Optical Engineering. 2015;9417:94170V.

187. Mooney JJ, Sarwani N, Coleman ML, Fotos JS. Evaluation of threedimensional printed materials for simulation by computed tomography and ultrasound imaging. Simul Healthc. 2017;12(3):182-188.
188. Biglino G, Capelli C, Wray J, et al. 3D-manufactured patient-specific models of congenital heart defects for communication in clinical practice: feasibility and acceptability. BMJ Open. 2015;5(4):e007165.

189. Olivieri LJ, Su L, Hynes CF, et al. "Just-In-Time" simulation training using 3-D printed cardiac models after congenital cardiac surgery. World J Pediatr Congenit Heart Surg. 2016;7(2):164-168.

190. Mcfarland CD, Thomas CH, Defilippis C, Steele JG, Healy KE. Protein adsorption and cell attachment to patterned surfaces. J Biomed Mater Res. 2000;49(2):200-210.

191. Bianchi ME. DAMPs, PAMPs and alarmins: all we need to know about danger. J Leukoc Biol. 2007;81(1):1-5.

192. Jones JA, Chang DT, Meyerson H, et al. Proteomic analysis and quantification of cytokines and chemokines from biomaterial surfaceadherent macrophages and foreign body giant cells. J Biomed Mater Res A. 2007;83A(3):585-596.

193. Defife KM, Jenney CR, Mcnally AK, Colton E, Anderson JM. Interleukin-13 induces human monocyte/macrophage fusion and macrophage mannose receptor expression. J Immunol. 1997;158(7): 3385-3390.

194. Aurora AB, Olson EN. Immune modulation of stem cells and regeneration. Cell Stem Cell. 2015;15:14-25.

195. Spiller KL, Koh TJ. Macrophage-based therapeutic strategies in regenerative medicine. Adv Drug Deliv Rev. 2017;122:74-83.

196. Wynn TA, Vannella KM. Macrophages in tissue repair, regeneration, and fibrosis. Immunity. 2016;44(3):450-462.

197. Julier Z, Park AJ, Briquez PS, Martino MM. Promoting tissue regeneration by modulating the immune system. Acta Biomater. 2017;53: 13-28.

198. Alvarez MM, Liu JC, Trujillo-de Santiago G, et al. Delivery strategies to control inflammatory response: modulating M1-M2 polarization in tissue engineering applications. J Control Release. 2016;240:349-363.

199. Projahn D, Simsekyilmaz S, Singh S, et al. Controlled intramyocardial release of engineered chemokines by biodegradable hydrogels as a treatment approach of myocardial infarction. $J$ Cell $\mathrm{Mol} \mathrm{Med}$. 2014;18(5):790-800.

200. Kim YS, Park HJ, Hong MH, et al. TNF-alpha enhances engraftment of mesenchymal stem cells into infarcted myocardium. Front Biosci. 2009; 14:2845-2856.

201. Chen WC, Lee BG, Park DW, et al. Controlled dual delivery of fibroblast growth factor- 2 and interleukin- 10 by heparin-based coacervate synergistically enhances ischemic heart repair. Biomaterials. 2015;72:138-151.

202. Prabhakaran D, Anand S, Watkins D, et al. Cardiovascular, respiratory, and related disorders: key messages from Disease Control Priorities, 3rd edition. The Lancet. 2018;391(10126):1224-1236.

203. Biglino G, Capelli C, Taylor AM, Schievano S. New Trends in 3D Printing. London: InTech; 2016.

204. Vukicevic M, Mosadegh B, Min JK, Little SH. Cardiac 3D printing and its future directions. JACC Cardiovasc Imaging. 2017;10(2):171-184.

205. Gui L, Dash BC, Luo J, et al. Implantable tissue-engineered blood vessels from human induced pluripotent stem cells. Biomaterials. 2016;102:120-129.

206. Dimitrievska S, Niklason LE. Historical perspective and future direction of blood vessel developments. Cold Spring Harb Perspect Med. 2018;8(2):a025742.

207. Mironov AV, Grigoryev AM, Krotova LI, et al. 3D printing of PLGA scaffolds for tissue engineering. J Biomed Mater Res A. 2017;105(1): 104-109.

208. Wang Z, Lee SJ, Cheng H-J, Yoo JJ, Atala A. 3D bioprinted functional and contractile cardiac tissue constructs. Acta Biomater. 2018; 70:48-56. 
International Journal of Nanomedicine

Dovepress

\section{Publish your work in this journal}

The International Journal of Nanomedicine is an international, peerreviewed journal focusing on the application of nanotechnology in diagnostics, therapeutics, and drug delivery systems throughout the biomedical field. This journal is indexed on PubMed Central, MedLine, CAS, SciSearch $®$, Current Contents $\circledR /$ Clinical Medicine,
Journal Citation Reports/Science Edition, EMBase, Scopus and the Elsevier Bibliographic databases. The manuscript management system is completely online and includes a very quick and fair peer-review system, which is all easy to use. Visit http://www.dovepress.com/ testimonials.php to read real quotes from published authors.

Submit your manuscript here: http://www.dovepress.com/international-journal-of-nanomedicine-journal 